\title{
The Value of Honesty: Empirical Estimates from the Case of the Missing Children*
}

\author{
Sara LaLumia ${ }^{\dagger}$ \\ Department of Economics \\ Williams College
}

\author{
James M. Sallee ${ }^{\ddagger}$ \\ The Harris School \\ University of Chicago
}

June 28, 2011

\begin{abstract}
How much are people willing to forego to be honest, to follow the rules? When people do break the rules, what can standard data sources tell us about their behavior? Standard economic models of crime typically assume that individuals are indifferent to dishonesty, so that they will cheat or lie as long as the expected pecuniary benefits exceed the expected costs of being caught and punished. We investigate this presumption by studying the response to a change in tax reporting rules that made it much more difficult for taxpayers to evade taxes by inappropriately claiming additional dependents. The policy reform induced a substantial reduction in the number of dependents claimed, which indicates that many filers had been cheating before the reform. Yet, the number of filers who availed themselves of this evasion opportunity is dwarfed by the number of filers who passed up substantial tax savings by not claiming extra dependents. By declining the opportunity to cheat, these taxpayers reveal information about their willingness to pay to be honest. We present a novel method for inferring the characteristics of taxpayers in the absence of audit data. Our analysis suggests both that this willingness to pay to be honest is large on average and that it varies significantly across the population of taxpayers.
\end{abstract}

Key words: Tax evasion, compliance, honesty, dependent exemption JEL codes: H26, H24

\footnotetext{
${ }^{*}$ The authors would like to thank Jon Bakija, Brian Erard, Bill Gentry, Jens Ludwig, Damon Jones, Lucie Schmidt, and Joel Slemrod for helpful comments.

${ }^{\dagger}$ Sara LaLumia, corresponding author, email: Sara.Lalumia@williams.edu; phone: 413-597-4886; fax: 413-5974045. web: http://lanfiles.williams.edu/ sl2/.

${ }^{\ddagger}$ James M. Sallee, email: sallee@uchicago.edu; web: http://home.uchicago.edu/ sallee.
} 


\section{Introduction}

The rational actor model that forms the basis for microeconomics has been fruitfully extended to many realms of human behavior, including criminal activity. The benchmark model of crime goes back to Becker (1968), which posits that an individual will commit a crime when the expected benefits exceed the expected costs. This same framework has been used to study the decision to evade taxation, beginning with the seminal contribution of Allingham and Sandmo (1972). These models assume that individuals face no psychological cost of breaking the law - they bear no intrinsic cost for being dishonest, but instead make a purely pecuniary calculation.

In the area of tax compliance, existing research has demonstrated a strong negative correlation between evasion and the probability of being caught, which broadly supports a model of rational calculation without refuting the possibility of a preference for honesty. For example, audit data show that sources of income that are not subject to third-party reporting are far more likely to be underreported (Klepper and Nagin 1989), to the extent that less than half of all income from self employment is claimed (Slemrod 2007). Recent research has pushed this claim further. Based on a randomized audit experiment, Kleven, Knudsen, Kreiner, Pederson and Saez (2010) conclude that "overall tax evasion is low, not because taxpayers are unwilling to cheat, but because they are unable to cheat successfully due to the widespread use of third-party reporting" (p. 3).

Yet, other authors have concluded that the observed levels of tax compliance are too high to be explained by the standard Allingham and Sandmo (1972) framework, arguing that some desire to be honest or to comply with social norms must be important (Andreoni, Erard and Feinstein 1998). Directly asking taxpayers does not clarify their motivations for compliance. In $2010,87 \%$ of taxpayers surveyed stated that it is not acceptable to cheat at all, and $97 \%$ agreed with the statement that "It is every American's civic duty to pay their fair share of taxes." But, $64 \%$ said that fear of audit was important in inducing them to pay their taxes honestly (Internal Revenue Service Oversight Board 2011). This paper contributes to the literature on tax compliance by using a novel strategy for detecting tax evasion and quantifying the willingness to pay to be honest, based on an examination of taxpayer response to a change in enforcement.

In 1987, millions of children suddenly "went missing" from the rolls of federal income tax returns. The reason was a change in reporting requirements, which eliminated an important avenue 
for evasion. To claim a dependent prior to 1987, a filer needed only to list the dependent's first name on his tax return. Since the Internal Revenue Service had no easy way to verify that these dependents existed or to ensure that they were not listed on multiple returns, the system may have tempted filers to either invent dependents or to claim ineligible individuals as dependents. Below, we show that many filers availed themselves of this opportunity and claimed fictitious or otherwise ineligible dependents. On the other hand, we estimate that a majority of taxpayers in our sample were unwilling to cheat to gain around $\$ 500$ in 2010 dollars, equivalent to roughly $1 \%$ of the mean after-tax income and $7 \%$ of the mean taxes owed in 1986. We interpret this as evidence that many taxpayers have a substantial taste for honesty, and that an unwillingness to cheat is thus an important component of the economics of tax evasion, and perhaps crime more generally. We also demonstrate how the response to the enforcement change can be used to uncover differences in characteristics across cheaters and honest taxpayers without relying on audit data. Our findings suggest that cheaters and honest taxpayers are fairly similar in many observable characteristics, including the tax value of cheating. ${ }^{1}$

Our analysis is performed on a panel of tax return data that spans the Tax Reform Act of 1986 (TRA86), which included the reporting change. As of 1987, filers were newly required to report a Social Security Number (SSN) for all dependents over the age of 5. Given this information, it was relatively easy for the IRS to verify the existence of dependents and to check that they were not listed on multiple returns, and consequently the probability of cheating without detection fell precipitously. The response to this change in reporting rules was pronounced. Our data show that the number of dependents claimed in 1987 fell by $5.5 \%$, which is equivalent to 4.2 "missing children".

We are not the first to document this decline in the number of dependents claimed. An IRS report detailed the motivation for the policy change and provided estimates of the change in the number of dependents claimed in response to the reform (Szilagyi 1990). Moreover, the episode is cited in two popular public finance texts (Slemrod and Bakija 2008; Gruber 2009) and a mainstream book on economics (Levitt and Dubner 2005). But, while the basic facts of this event are known,

\footnotetext{
${ }^{1} \mathrm{~A}$ number of studies using audit data have tested for differences in evasion across income categories, gender and tax rates (Clotfelter 1983; Feinstein 1991; Christian 1994). These articles do not, however, indicate whether these evasion differences are due to different opportunities to evade or different propensities conditional on opportunity. Our case study has the advantage of being an opportunity that is readily available to all taxpayers, which allows us to isolate evasion predilection.
} 
no prior work has studied the behavioral responses in detail, nor has any other research used this incident to quantify evasion, measure the willingness to pay to be honest, or estimate the differences in characteristics between honest taxpayers and cheaters, as we do here.

Early waves of empirical research on tax evasion were based on audit data, survey data and laboratory experiments, each of which has strengths and weaknesses. ${ }^{2}$ Our work relates more closely to a newer stream of research that uncovers indirect evidence of evasion, which Slemrod and Weber (Forthcoming) call "traces of evasion." An early example of this strategy is Pissarides and Weber (1989), which compares national income product account and reported taxable income to infer underreporting. Feldman and Slemrod (2007) infer evasion by comparing the marginal increase in charitable donations with respect to sources of income subject to different third-party reporting requirements. Our analysis differs from these by leveraging a natural experiment from a change in enforcement policy to uncover facts about evasion without the benefit of audit data. ${ }^{3}$

Researchers within and outside of economics have incorporated a variety of social factors into models of compliance. Tyler (1990) argues that citizens obey the law out of a sense of allegiance to a government they view as a legitimate authority. Smith (1992) applies this idea to the case of tax filing, documenting with survey evidence that self-reported voluntary compliance is positively correlated with viewing the tax authority as fair and responsive. Cowell (1992) considers a general model of evasion where the equity of the tax system influences preferences without specifying a functional form, and Bordignon (1993) models an environment in which social concerns create a constraint on the amount of evasion available. Related implications have been tested in laboratory experiments. There is evidence that evasion responds to cues about fairness (Spicer and Becker 1980) and to the uses of revenue (Becker, Büchner and Sleeking 1987).

The models most closely related to our work incorporate honesty directly. Block and Heineke (1975) introduce a "preference for honesty" into a labor supply model, allowing the disutility of work to differ for activities that are legal versus illegal. Erard and Feinstein (1994) introduce compliance behavior by assuming that some fraction of consumers will never cheat. Gordon (1989), which

\footnotetext{
${ }^{2}$ For a thorough discussion and critique of the literature see Andreoni et al. (1998) and Slemrod (2007). Of particular interest to our work is the finding from laboratory studies that some people comply with the tax authority, even when the probability of audit is known to be zero, which implies a desire to be honest (Baldry 1987; Alm, McClelland and Schulze 1992)

${ }^{3}$ Our approach also has an affinity with non-income-tax studies that uncover cheating indirectly, such as Jacob and Levitt (2003), Fisman and Wei (2004), and Oliva (2010).
} 
is perhaps most similar to our model, adds a psychic cost to the Allingham and Sandmo (1972) framework where the consumer faces a continuous evasion choice. Individuals with the highest psychic costs rarely evade, but, assuming decreasing absolute risk aversion, are predicted to evade more when the tax rate increases. Our model is distinct from existing work in analyzing a discrete choice to cheat (by claiming a dependent) and in providing a direct parameterization that we take to data in order to quantify the willingness to pay to be honest.

Our analysis proceeds as follows. In section 2, we provide additional details about the change in reporting policy and the other tax law modifications in TRA86 relevant to our analysis. In section 3 we describe our data, which is a panel of tax returns spanning the reform. In section 4 we document the decline in the number of dependents claimed in 1987. We argue that the substantial decline cannot be accounted for by other changes in dependent rules that were part of TRA86.

In section 5 we flip to the other side of the coin and document the tax savings foregone by the majority of filers who did not claim additional dependents and were therefore unaffected by the policy reform. We show that average tax savings given up by honest taxpayers from claiming one inappropriate dependent would have been roughly $\$ 250$ in 1986 dollars on average, which equates to $\$ 500$ in 2010 dollars, or $1 \%$ of after-tax income and $7 \%$ of the average total tax paid. We show that accounting for risk preferences has a limited impact on these magnitudes.

In section 6 we impute the average characteristics of cheaters, as compared to groups of honest taxpayers, and conclude that they look different on several dimensions, including filer status and claiming of the Child Care Credit. The average cheater does not, however, appear to have a higher monetary gain from cheating than the average honest taxpayer. This suggests that the variation in the decision to cheat is not driven primarily by the tax savings at stake, but instead by variation in the willingness to pay to be honest. We interpret this as a second piece of evidence in support of the notion that a taste for honesty is quantitatively important for the analysis of evasion. Section 7 concludes.

\section{The introduction of Social Security information on tax returns}

Prior to 1987, a tax filer needed to include only the first names of any dependent children he wished to claim on his return. In contrast, starting in 1987, the 1040 required the full name and SSN of all 
Figure 1: The Change in Reporting Required on the 1040

(a) 1986 Exemption Portion of the 1040

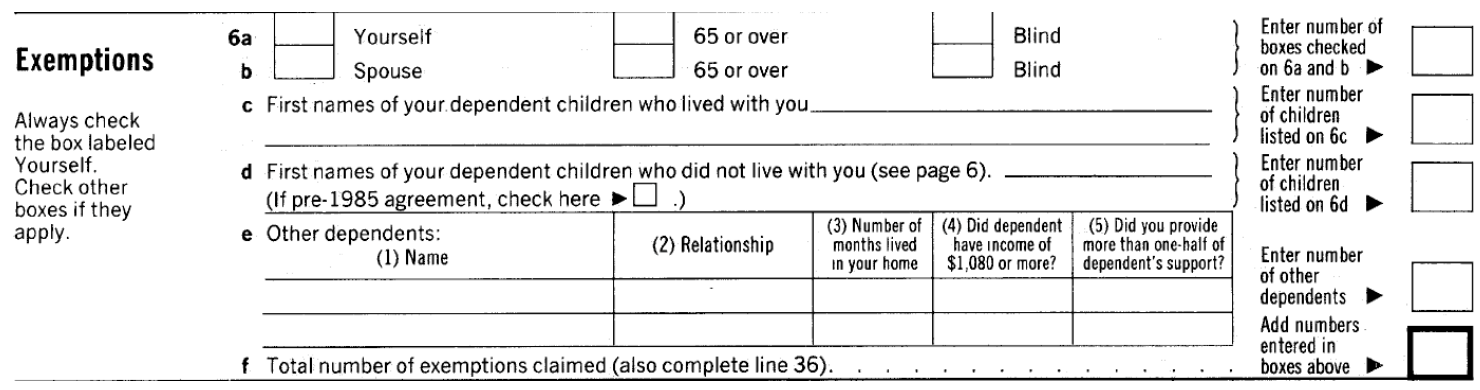

(b) 1987 Exemption Portion of the 1040

\begin{tabular}{|c|c|c|c|c|c|c|c|}
\hline \multirow{3}{*}{$\begin{array}{l}\text { Exemptions } \\
\text { (See } \\
\text { Instructions } \\
\text { on page 7.) }\end{array}$} & \multicolumn{6}{|c|}{$\begin{array}{l}\text { Caution: If you can be claimed as a dependent on another person's tax return (such as your parents' return), } \\
\text { do not check box } 6 a \text {. But be sure to check the box on line } 32 \text { b on page } 2 \text {. }\end{array}$} & \multirow{3}{*}{$\begin{array}{l}\text { No. of boxes } \\
\text { checked on } 6 a \\
\text { and } 6 b \\
\text { No. of children } \\
\text { on } 6 c \text { who lived }\end{array}$} \\
\hline & $6 a$ & Yourself & & \multicolumn{3}{|l|}{ Spouse } & \\
\hline & c & $\begin{array}{l}\text { Dependents } \\
\text { (1) Name (first, Initial, and last name) }\end{array}$ & $\begin{array}{l}\text { (2) Check } \\
\text { if under } \\
\text { age } 5\end{array}$ & $\begin{array}{l}\text { (3) If age } 5 \text { or over, dependent's } \\
\text { social security number }\end{array}$ & (4) Relationshıp & $\begin{array}{c}\text { (5) No. of months } \\
\text { lived in your home } \\
\text { in } 1987\end{array}$ & \\
\hline \multirow{8}{*}{$\begin{array}{l}\text { If more than } 7 \\
\text { dependents, see } \\
\text { Instructions on } \\
\text { page } 7 .\end{array}$} & & & & $\vdots$ & & & \multirow{4}{*}{$\begin{array}{l}\text { No. of children } \\
\text { on } 6 \mathrm{c} \text { who didn't } \\
\text { live with you due } \\
\text { to divorce or } \\
\text { separation } \\
\text { No. of parents }\end{array}$} \\
\hline & & & & $\vdots$ & & & \\
\hline & & & & $\vdots$ & & & \\
\hline & & & & $\vdots$ & & & \\
\hline & & & & $\vdots$ & & & \multirow{3}{*}{$\begin{array}{l}\text { listed on } 6 c \\
\text { No. of other } \\
\text { dependents } \\
\text { listed on } 6 c\end{array}$} \\
\hline & & & & $\vdots$ & & & \\
\hline & & & & $\vdots$ & & & \\
\hline & & \multicolumn{5}{|c|}{$\begin{array}{l}\text { d If your child didn't live with you but is claimed as your dependent under a pre-1985 agreement, check here } \\
\text { e Total number of exemptions claimed (also complete line 35) }\end{array}$} & $\begin{array}{l}\text { Add numbers } \\
\text { entered in } \\
\text { boxes above }\end{array}$ \\
\hline
\end{tabular}

Note: The figure shows portions from the 1040 form in 1986 and 1987. The 19861040 required only the first names of dependents, whereas the 1987 required the full name, birth date and Social Security Number for all children over age 5 .

children over age 5. The relevant portions of the 1040 from 1986 and 1987 are shown in figure 1. The SSN requirement was extended to all dependents age 2 and older beginning in tax year 1989, to all dependents at least one year old in 1991, and finally to all dependents in 1995 . $^{4}$ The IRS took this step out of concerns that there was significant misreporting. Regular audits had revealed that a significant fraction of audited tax returns involved adjustments for personal exemptions that were disallowed (Szilagyi 1990). The gradual reduction in ages affected by the SSN requirement was designed to give families time to obtain Social Security Numbers for children. ${ }^{5}$

While the reporting requirement for claiming a dependent exemption changed in 1986, the

\footnotetext{
${ }^{4}$ In the early years of the dependent SSN requirement, the IRS did little verification of this new information. Only 3 percent of dependent SSNs were computer matched to uncover dual claiming of dependents or violations of the age and income tests (General Accounting Office 1993).

${ }^{5}$ Today more than $90 \%$ of SSNs issued to children are issued at the time of birth (GAO 2005). This is made possible through the Enumeration at Birth program, launched in 1989. This partnership between the Social Security Administration and state vital statistics agencies allows parents to request an SSN for their child as part of the birth certificate registration process.
} 
underlying definition of a dependent did not change. Five tests must be met in order for a taxpayer to claim another individual as a dependent. The dependent must be a U.S. citizen or a resident of the U.S., Canada, or Mexico. The dependent cannot file a joint return. The dependent's income cannot exceed the personal exemption amount, with exceptions made for a taxpayer's own child under the age of 19 or under the age of 24 if a full-time student. The dependent must either live with or be related to the taxpayer claiming her. Finally, more than half of the dependent's support must be provided by the taxpayer claiming her. None of these tests changed between 1986 and 1987. Analysis by the General Accounting Office (1993) shows that, with the SSN requirement in place, violations of the support test are the most common reason for a dependent exemption to be disallowed. ${ }^{6}$

The Tax Reform Act of 1986 did make changes that may have influenced the dependent status of some individuals. Prior to the reform, a child who was claimed as a dependent by his parents but who also filed his own return could claim a personal exemption for himself. This "double-dipping" was eliminated by TRA86. Beginning in 1987, dependents were not permitted to claim a personal exemption and in most cases could claim only a limited standard deduction. This may have created some negotiation between parents and children about how long to remain a dependent. ${ }^{7}$ The value to parents of claiming an additional exemption also changed in 1986 . The nominal value of a personal exemption rose from $\$ 1080$ to $\$ 1900$ while marginal tax rates fell for most taxpayers. We return to these changes below when interpreting our data.

\section{Tax return panel data}

We use data from the University of Michigan tax panel, compiled by the Office of Tax Policy Research (OTPR). The starting point for this dataset is the annual cross-sections of tax return data released by the Statistics of Income (SOI) division of the IRS. These cross-sections report

\footnotetext{
${ }^{6}$ Recent research on dependent overclaiming focuses on the Earned Income Tax Credit (EITC). McCubbin (2000) describes data from a 1994 audit of randomly selected EITC claimants. Approximately 26\% of EITC dollars claimed were overturned upon audit, and about $70 \%$ of these overclaims involved an error in claiming an EITC-qualifying child. McCubbin further finds that misclaiming a child is sensitive to the size of the associated benefit. She estimates that a $\$ 100$ increase in the tax savings from claiming a child increases the probability of erroneously claiming an EITC-qualifying child from a mean of $8 \%$ to $8.4 \%$. Liebman (2000) estimates the extent of EITC misclaiming by matching March 1991 CPS respondents to 1990 tax return data. At the time, the EITC was exclusively available to filers with children. Liebman estimates that 11 to $13 \%$ of 1990 EITC recipients did not have a child in their CPS household as of March 1991, and 10\% did not have a child in the household one year earlier.

${ }^{7}$ See Whittington and Peters (1996) for evidence that the tax effect on this decision is small.
} 
information from most lines of the tax return and from many supporting schedules. There is information on the total number of exemptions (including extra exemptions for filers who are blind or over age 65), the number of exemptions for dependent children (reported separately for children living at home and children living away from home), and the number of exemptions for dependents other than children. To protect taxpayer confidentiality, income amounts are blurred and the number of exemptions is topcoded in some cases. ${ }^{8}$ The panel links the tax returns of individuals who appear in multiple SOI cross-sections from 1979 to 1990.

Selection into the panel is based on the last four digits of the primary filer's SSN. The number of four-digit combinations included in the panel changed over time, leading to wide variation in the number of tax returns included in different years. Approximately 45,000 returns are included in the years with the most widespread coverage, while slightly over 9,000 returns are included in tax years 1982, 1984, and 1986. The number of tax filing units present in all 12 years of the panel is 4,982, and the number present in both 1986 and 1987 is 9,099. A change in marital status may cause an individual to be dropped from the panel, as only the SSN of the primary filer is used in linking returns across years. If an individual has been filing as a single person, marries, and is subsequently listed as the secondary filer, returns from before and after her marriage will not be linked. On the other hand, if she is listed as the primary filer after marriage her returns will be linked. Similarly, if a married couple divorces only the primary filer will be tracked over the remainder of the panel. Because men are more likely to be listed as primary filers, men have lower rates of attrition from the tax panel. In contrast to other longitudinal datasets, there is no reason to expect movers to exit from the panel, unless they stop filing tax returns. The taxpayer's address is not used in linking cross-sectional files.

\section{Many people cheated on their tax returns}

Our tax panel data allow us to look at the number of filers who lose net dependents each year by comparing the number of dependents in one year against the number claimed the following year. If many filers were cheating up until 1986, then we would expect to see a large number of filers

\footnotetext{
${ }^{8}$ For returns with adjusted gross income (AGI) greater than $\$ 200,000$, the number of exemptions for children living at home is topcoded at 3. This topcoding is unlikely to affect our results, as only 7 filing units observed in both 1986 and 1987 are affected. The number of filing units affected in any other pair of years over which dependent loss is calculated is never greater than 22 .
} 
Figure 2: Percentage of Tax Filers Who Lose and Gain At Least One Dependent Each Year

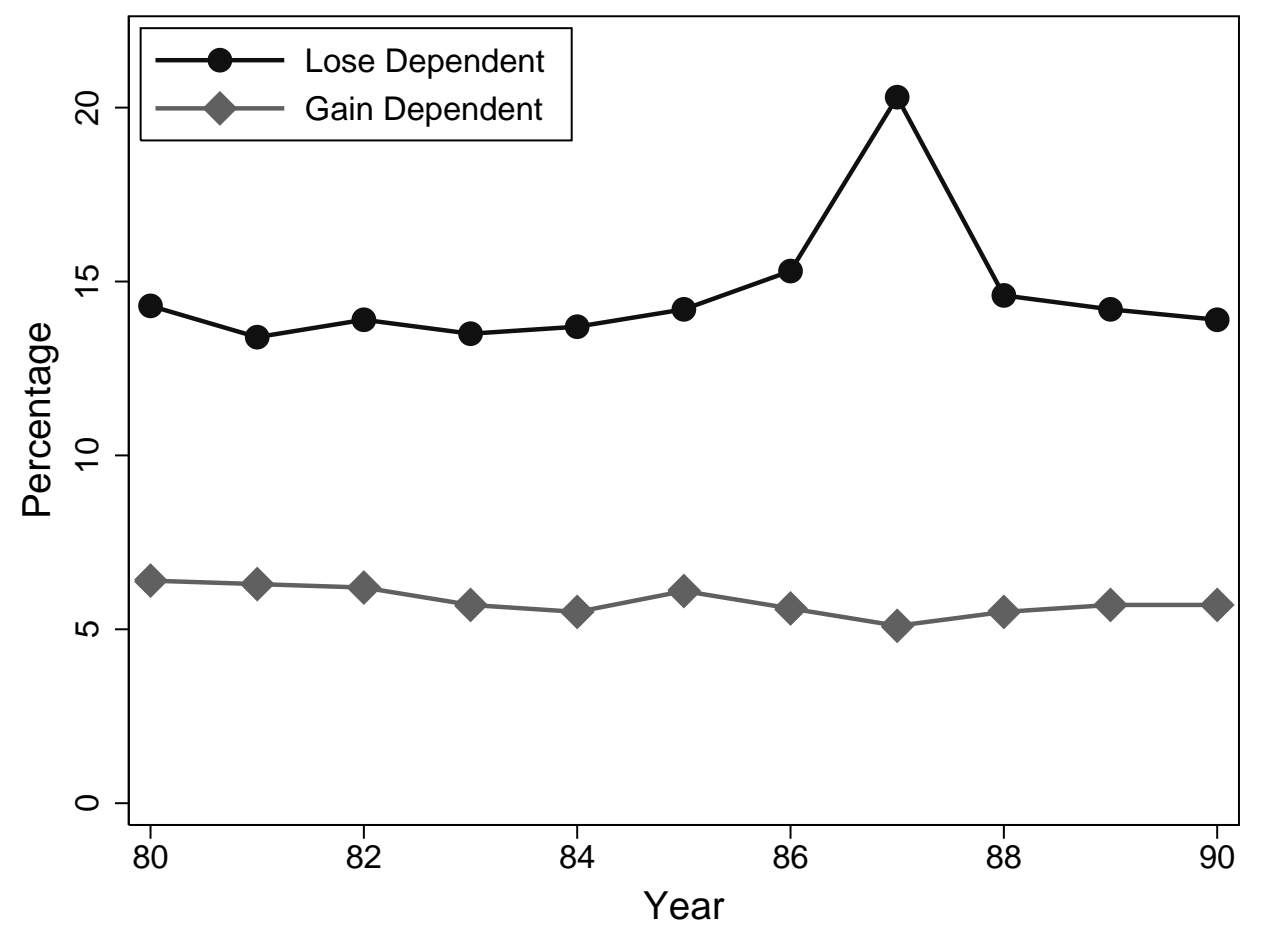

Note: Estimates are the authors' calculations from the OTPR tax panel. The number of dependent exemptions claimed is the sum of exemptions for children living at home, children living away from home, parents, and other dependents. In computing the share of returns losing dependents in year $t$, the denominator is the set of filing units observed in both $t$ and $t-1$ and claiming a positive number of dependent exemptions in $t-1$. In computing the share of returns gaining dependents in year $t$, the denominator is all filing units observed in both $t$ and $t-1$.

losing dependents in 1987. Figure 2 plots the percentage of filers who lost at least one dependent in each year of our panel, conditional on claiming a dependent in the previous year. There is a dramatic spike in 1987 , when $20.3 \%$ of filers lose a dependent, compared to an average of $14.0 \%$ in all other years. ${ }^{9}$ The number of "excess" dependent-losing filers in 1987 is equal to $2.5 \%$ of the filing population. Figure 2 also plots the fraction of filers who gain at least one dependent in each year, which shows no commensurate change between 1986 and 1987. Some cheaters may have chosen to claim more than one fictitious dependent. The percentage of filers losing multiple dependents is

\footnotetext{
${ }^{9}$ There are other cases in which requiring a taxpayer to provide a straightforward piece of supporting evidence has generated a large change in reporting. Fack and Landais (2011) show that when France first required that receipts be submitted with the tax return for any charitable contributions claimed, reported charitable contributions fell by $75 \%$.
} 
Figure 3: Number of Dependents Claimed on Tax Returns Relative to Number of Children in the Population

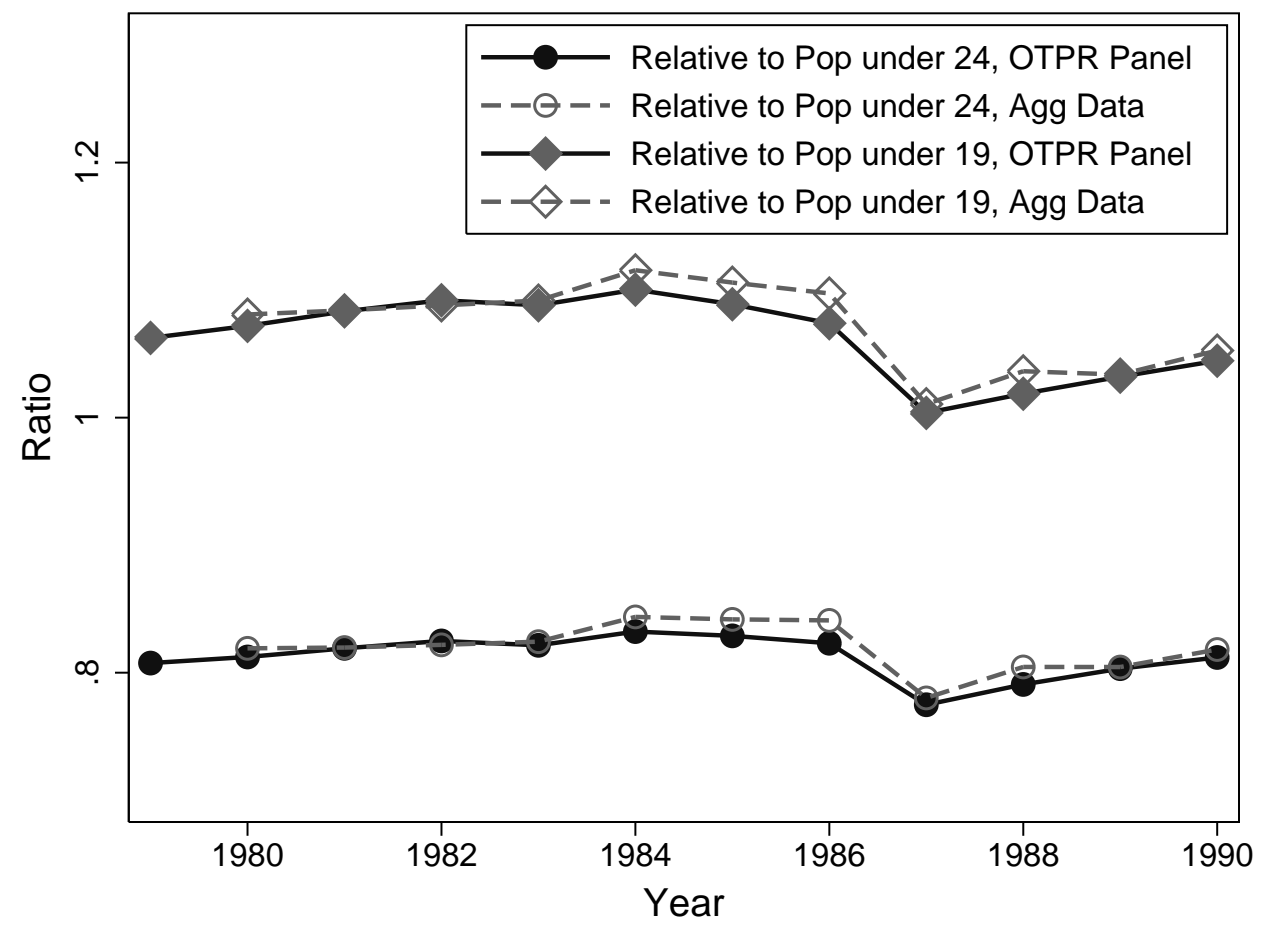

Note: Estimates of the population under 19 and under 24 come from the United States Census Bureau. Estimates of the number of child dependents claimed on tax returns (including children living at home and children living away from home) are the authors' calculations from the OTPR tax panel.

$4.4 \%$ in 1987 , substantially greater than the $2.2 \%$ to $2.9 \%$ losing multiple dependents in any other year of the panel. We view this as further evidence of cheating, but throughout the paper we focus on the decision to claim a marginal extra dependent.

We can also compare the number of child dependents claimed on tax returns to the number of children in the population from Census estimates. Figure 3 shows the ratio of the number of child dependent exemptions claimed (for children living at home and children living away from home) to the number of children under age 19 and to the number of children under age 24. Most people under age 19 are eligible to be claimed as dependents, but we expect this ratio to be less than one due to non-filing. Many people between ages 19 and 23 who are full-time students will also be eligible to be claimed as a dependent. As is evident in the figure, the relationship between the number of child dependents and the number of children in the population was quite steady 
until 1987, at which time there was a significant fall in the number of dependents that does not correspond to any change in the underlying population. This pattern is evident both in the OTPR panel data (solid lines) and in aggregate child dependent counts (dashed lines). ${ }^{10}$ Despite the small size of the OTPR panel, the values we impute from it are a close match to values computed from aggregate data.

A simple estimate of the number of inappropriate dependent claims can be derived under the assumption that filers lost more dependents in 1987 than in other years solely because many people were cheating prior to the reform, but stopped cheating in 1987. Under that assumption, the "extra" dependent losses observed in the panel between 1986 and 1987 correspond to 4.2 million improperly claimed dependents, or $5.5 \%$ of all dependents claimed in $1986 .{ }^{11}$ These estimates are broadly similar to the conclusion reached by an IRS research report, which concluded that the reform lowered the number of dependents claimed by around 7 million, or 9\% (Szilagyi 1990). Szilagyi (1990) also reports that the 1987 policy change reversed a long-run trend in the number of dependent exemptions that were determined to be erroneous in the Tax Compliance Management Program data, which shows a rise from $4.3 \%$ of dependent exemptions being erroneous in 1965 to $11.2 \%$ in 1979.

\subsection{Could the change in dependents be due to those lacking SSNs?}

The policy reform in 1987 required that filers record the Social Security Number of dependents to be claimed, but not all people have a Social Security Number. Could the spike in dependent reductions be due to many dependents not having an SSN, and thus being left off of the return?

Several factors weigh against this explanation. First, in 1987, children under the age of 5, who were the most likely not to have an SSN, were exempted from the requirement. Second, we suspect that anyone who stood to gain from having a dependent exemption would have acquired an SSN for the relevant dependent upon learning of the requirement. Data from the Social Security Administration support this view, showing a surge in SSN applications shortly after the policy

\footnotetext{
${ }^{10}$ Aggregate data on the number of child dependent exemptions claimed come from the annual IRS publication 1304, and were generously provided to us by Brian Erard.

${ }^{11}$ TRA 86 increased the value of the standard deduction and the personal exemption, which increased the income at which a person is required to file a tax return. This change in the filing threshold could cause children of low-income parents to disappear from tax data if their parents are no longer required to file. If we restrict our sample to filing units with real income above the 1987 filing threshold, we estimate a loss of 3.8 million dependents between 1986 and 1987.
} 
Figure 4: Share Gaining a Dependent, Among Those Losing Dependent in Year 0

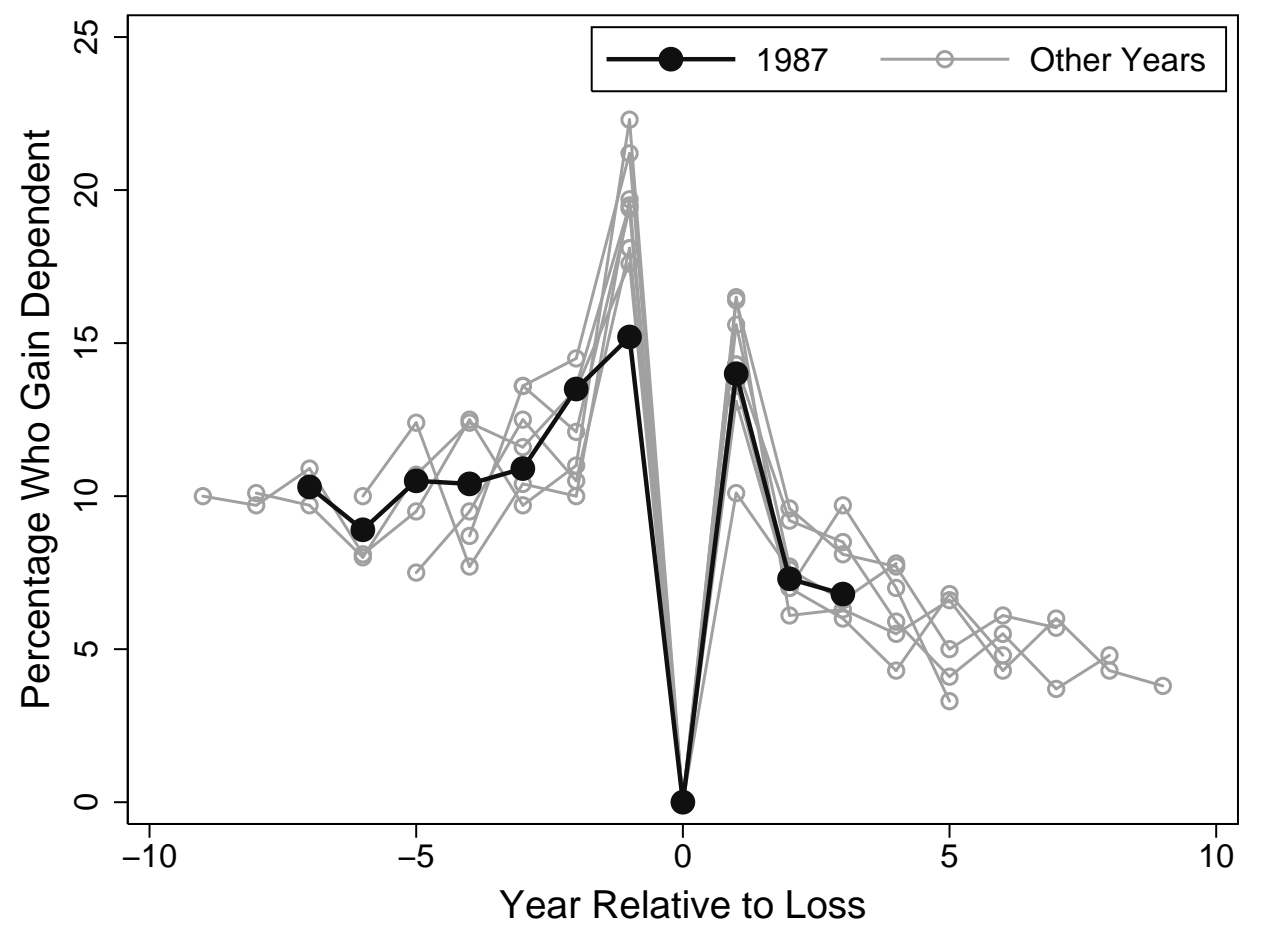

Note: Each line in the figure corresponds to a different subsample from the OTPR panel, the set of filing units losing at least one dependent in a particular year. The bold line corresponds to the 721 filing units observed losing at least one dependent in 1987 . We follow each sample over time, computing the share of these filing units gaining a dependent in each earlier and later year.

change. The number of new SSNs issued had been between 5.4 and 6.7 million in each year from 1980 to 1986 . This number increased to 11.6 million in 1987, 11.4 million in 1988 , and then gradually fell back to pre-87 levels by 1993 .

Finally, if many filers failed to claim true dependents in 1987 because of the SSN requirement, we expect that they would have acquired an SSN for these dependents in subsequent years. This would imply that people who lost a dependent in 1987 should have been especially likely to gain a dependent in the subsequent several years, once they had acquired the SSN.

To look for this pattern, figure 4 plots the fraction of filers gaining a dependent, conditional on having lost a dependent in a particular year. The horizontal axis measures time relative to the year in which a dependent was lost. Each line represents a different set of filers, those losing a dependent in a given year of the sample. The bold line shows filers who lost dependents in 1987. 
Overall, the data show considerable churning. Relative to year zero (when a filer lost a dependent), filers are relatively likely to have gained a dependent immediately before or after that loss. This results in part from short-lived marriages in which one member of the couple has children and from confusion about who can claim a dependent following a divorce. If many filers lost a dependent in 1987 because of missing SSNs, we would have expected a large increase in dependent gains for those filers in subsequent years, relative to the gain experienced by filers who lost dependents in nonreform years. This is not the case; 1987 appears typical. If anything, gains are low immediately after 1987 losses, which is consistent with cheaters being less likely than legitimate losers of dependents to regain the dependent in the subsequent year. ${ }^{12}$

\subsection{Could the change in dependents be due to other changes in TRA86?}

The Tax Reform Act of 1986 involved many other tax changes. Could any of these be the source of a large reduction in dependents? The most obvious feature of TRA86 relevant here is a change in the tax treatment of dependent filers. Prior to 1986, a child who filed his own return could claim a personal exemption on his return and still be claimed as a dependent by his parents. After 1987, this was not allowed, so children and parents had to choose whether the child would file with zero exemptions, and allow the parents to claim the exemption, or vice versa. If many families chose to allow income-earning children, who qualified as dependents, to claim themselves instead of claiming them as dependents on the parents' return, then this could generate a one-time drop in dependents claimed in 1987.

The number of such cases is likely to be small, however, because the exemption would have rarely been worth more in tax savings to children than to parents. The value of the exemption depends entirely on the marginal tax rate. Thus, in short, for it to be tax-minimizing for a child to claim herself, that child would need to earn sufficiently more money than her parents so as to be in a higher tax bracket, and yet still live in her parents' home and obtain more than $50 \%$ of her financial support from her parents, so as to qualify as a dependent.

Such arrangements are rare, as is shown in table 1, which uses March Current Population Survey

\footnotetext{
${ }^{12}$ Aggregate data on total annual dependent counts are consistent with the view that most of the dependents lost in 1987 did not reappear in later years. The total number of dependents claimed divided by the total number of returns filed had been above 0.75 in years 1980-1985, fell from 0.75 in 1986 to 0.67 in 1987, and hovered between 0.66 and 0.69 over the next ten years. We thank Brian Erard for pointing us toward this evidence.
} 
Table 1: Children's Income Relative to Parents' Income

\begin{tabular}{lccc}
\hline \hline & Full Sample & Ages 15-18 & Ages 19-23 \\
A. Wage Income & & & \\
\% with Any & 54.7 & 47.6 & 77.8 \\
Mean Amount & 1,317 & 836 & 2,883 \\
\% with Wages > 0.75· Parents' Wages & 6.2 & 5.5 & 8.5 \\
\% with Wages > Parents' Wages & 5.7 & 5.1 & 7.3 \\
Median of (Own Wages/Parents' Wages) & 0.007 & 0 & 0.049 \\
B. Total Income & & & \\
\% with Any & 66.2 & 59.8 & 86.9 \\
Mean Amount & 1,874 & 1,229 & 3,977 \\
\% with Inc > 0.75. Parents' Inc & 2.8 & 2.5 & 3.6 \\
\% with Inc > Parents' Inc & 2.0 & 1.8 & 2.6 \\
Median of (Own Inc/Parents' Inc) & 0.015 & 0.005 & 0.068 \\
$\mathrm{~N}$ & 11,369 & 8,853 & 2,516 \\
\hline \hline
\end{tabular}

Data are from the March 1987 CPS, available via IPUMS. The sample is restricted to children of household heads, and to those either between the ages of 15 and 18 or between the ages of 19 and 23 and enrolled in school full-time.

(CPS) data from 1987. We constructed a sample of children, between the ages of 15 and 23, living with one or both parents. The lower age cutoff reflects the fact that only individuals aged 15 or older report income information in the CPS. All children between ages 15 and 18 are included, while children between ages 19 and 23 are included only if they are full-time students. Table 1 shows that $66.2 \%$ of these potential dependents had some form of income, and $54.7 \%$ had wage income. Not surprisingly, the median ratio of a child's income to his parents' income is 0.015 . Only $2.8 \%$ of children had income equal to $75 \%$ of their parents' income, and just $2 \%$ had income equal to or greater than their parents'.

In sum, given the low probability that it would have been tax-minimizing for children to claim themselves, we expect that this aspect of the TRA86 reform is unlikely to explain an important fraction of the drop in dependents. The vast majority of the missing dependents were likely from filers who had been cheating prior to the enforcement reform. 


\section{Many other people paid to be honest}

Our data suggest that around $2.5 \%$ of taxpayers were cheating by improperly claiming dependents in 1986. Conversely, this means that $97.5 \%$ were not cheating in this way. This is perhaps the more surprising statistic, given the substantial amount of income that could have been taken at relatively low risk by claiming fraudulent dependents. Importantly, the $97.5 \%$ of tax payers who did not avail themselves of this opportunity to cheat implicitly demonstrated that they would rather give up several hundred dollars in income than cheat the government. Overall, we think this is striking evidence of a broad willingness to pay to be honest across the taxpayer base.

How much did honest taxpayers forgo? Ideally, to answer this question we would like to eliminate the tax cheaters from the sample and tabulate the distribution of tax savings from claiming an extra dependent that would have been enjoyed by the honest taxpayers had they cheated. Unfortunately, there is no way to directly identify the cheaters in the data. We can, however, identify groups of filers who were almost certainly honest. One such group is the set of filers who did not lose a dependent between 1986 and 1987, who make up 92\% of filers. Below, in section 6, we show how similar assumptions can be combined with estimates of the number of cheaters to infer differences in average characteristics between cheaters and honest payers. Here, we focus just on the tax values of honest payers.

Table 2 shows the average 1986 tax savings associated with the marginal dependent for filers who appear in the panel in both 1986 and 1987. These statistics are obtained by comparing the after-tax income of filers given the actual number of dependents reported in the data against their hypothetical after-tax income when they have one additional (or one fewer) dependent, as calculated by TAXSIM. ${ }^{13}$ The after-tax income gain that would have accrued to families from claiming one additional child represents the gain to be had from cheating. On average, those who did not lose a dependent between 1986 and 1987 would have saved $\$ 275$ on their 1986 taxes by claiming an additional dependent. The mean savings is even higher, $\$ 291$, for those who claimed zero dependents. We view both of these groups as consisting of honest taxpayers. These savings are in 1986 dollars; inflating by the CPI to 2010 dollars doubles the estimates to $\$ 547$ and $\$ 579 .{ }^{14}$

Are these tax savings, foregone in the interest of civic piety, large? To put the magnitudes in

\footnotetext{
${ }^{13}$ The TAXSIM program is described by Feenberg and Coutts (1993).

${ }^{14}$ We use the CPI-U all items, which was 109.6 in 1986 and almost exactly double, 218.1, in 2010.
} 
Table 2: The Value of Claiming a Dependent

\begin{tabular}{|c|c|c|c|c|c|}
\hline & $\mathrm{N}$ & $\begin{array}{c}\text { Gain from } \\
\text { Additional } \\
\text { Dep, } 1986\end{array}$ & $\begin{array}{l}\text { Loss from } \\
\text { One Fewer } \\
\text { Dep, } 1986\end{array}$ & $\begin{array}{l}\text { After-Tax } \\
\text { Income }\end{array}$ & Tax Liability \\
\hline Observed in 86 and 87 & 9,099 & $\begin{array}{c}271 \\
(160)\end{array}$ & & $\begin{array}{c}22,006 \\
(28,108)\end{array}$ & $\begin{array}{c}3,898 \\
(16,573)\end{array}$ \\
\hline No deps in 1986 & 5,548 & $\begin{array}{c}291 \\
(176)\end{array}$ & & $\begin{array}{c}17,878 \\
(27,030)\end{array}$ & $\begin{array}{c}3,509 \\
(18,081)\end{array}$ \\
\hline Deps in 1986 & 3,551 & $\begin{array}{c}239 \\
(123)\end{array}$ & $\begin{array}{l}-271 \\
(126)\end{array}$ & $\begin{array}{c}28,457 \\
(28,546)\end{array}$ & $\begin{array}{c}4,505 \\
(13,875)\end{array}$ \\
\hline Lost dep in 1987 & 721 & $\begin{array}{c}224 \\
(121)\end{array}$ & $\begin{array}{l}-254 \\
(127)\end{array}$ & $\begin{array}{c}25,868 \\
(25,888)\end{array}$ & $\begin{array}{c}3,943 \\
(11,082)\end{array}$ \\
\hline Didn’t lose in 1987 & 2,830 & $\begin{array}{c}243 \\
(123)\end{array}$ & $\begin{array}{l}-276 \\
(126)\end{array}$ & $\begin{array}{c}29,117 \\
(29,152)\end{array}$ & $\begin{array}{c}4,648 \\
(14,499)\end{array}$ \\
\hline Didn’t lose dep in 1987 & 8,378 & $\begin{array}{c}275 \\
(162)\end{array}$ & & $\begin{array}{c}21,674 \\
(28,268)\end{array}$ & $\begin{array}{c}3,894 \\
(16,964)\end{array}$ \\
\hline
\end{tabular}

Calculations of the gain (loss) associated with claiming one additional (fewer) dependent rely on TAXSIM estimates of tax liability, using income elements and household composition reported on 1986 tax returns. Standard deviations are in parentheses. After-tax income is defined as AGI minus total income tax liability, as reported on 1986 tax returns.

context, table 2 also shows the average after-tax income and average income tax paid for filers across these categories. The foregone gains from cheating, among those who did not lose a dependent in response to the reform, amount to $1.3 \%$ of after-tax income, and $7.1 \%$ of taxes paid. These are substantial amounts.

Figure 5 shows the distribution of tax savings that would have accrued to filers if they had claimed an additional dependent in 1986, for the sample of returns that did not lose dependents between 1986 and 1987 (and are therefore assumed to be honest payers). Dependent exemptions are non-refundable, so claiming an additional dependent has zero impact for low-liability filers. Among those not losing a dependent between 1986 and 1987, 7.3\% would have gained nothing. The average tax savings from an additional dependent among the remaining filers was larger. In this sample of presumably honest taxpayers, $69.4 \%$ stood to gain at least $\$ 200$, and $18.0 \%$ stood to gain at least $\$ 400$ by claiming an extra dependent.

In real dollars, the average foregone tax savings presented in table 2 are as large as the Child Tax Credit when it was introduced in 1998, and they are $80 \%$ of the size of the maximum tax rebate for single filers in the 2008 stimulus plan. Moreover, past research has found evidence of fertility 
Figure 5: Value of Claiming One Additional Dependent, Non-Losers, 1986

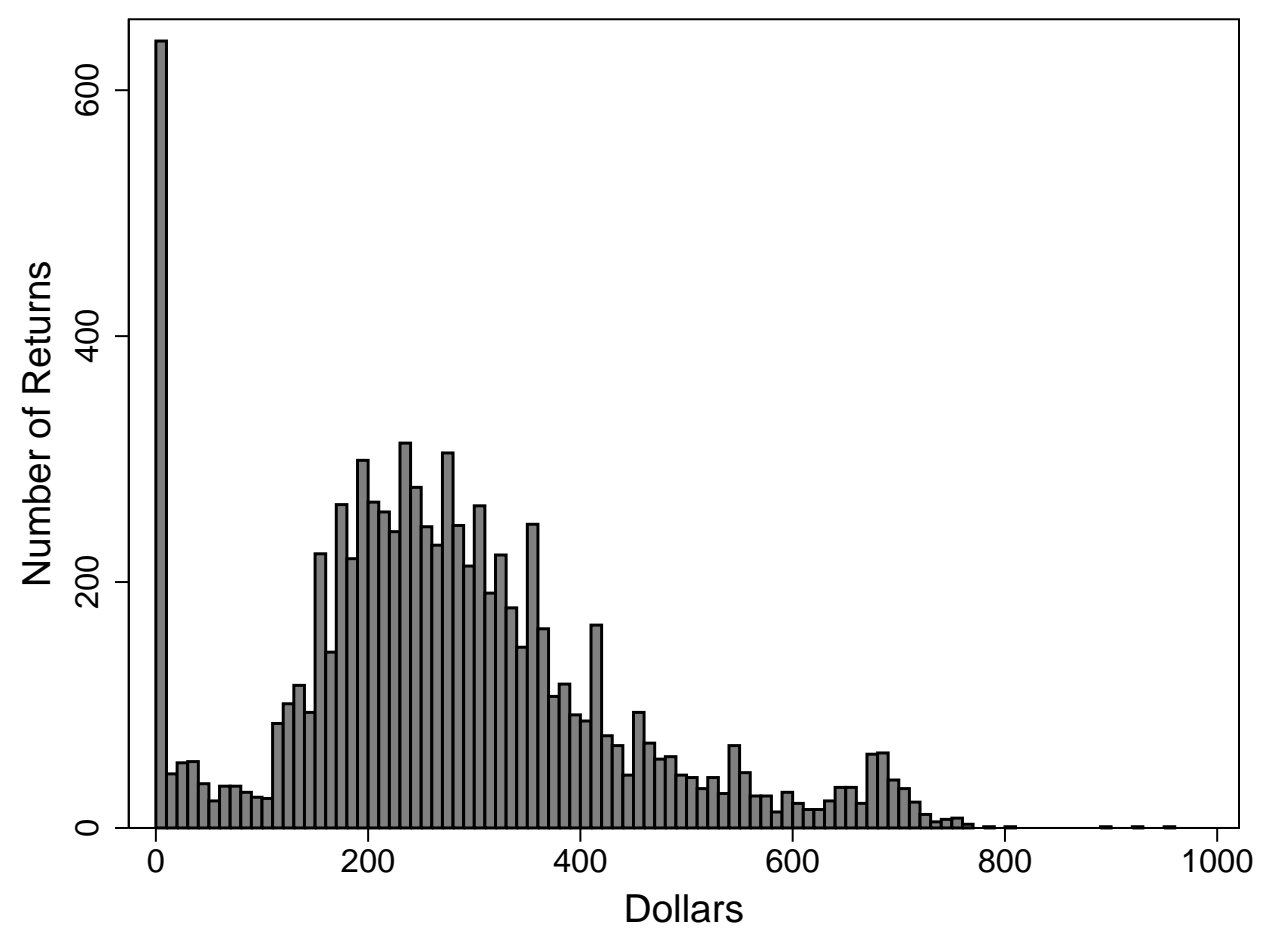

Note: Filing units that appear in both 1986 and 1987, and that do not lose a dependent between these years, are included in this figure. The figure graphs the difference between two tax liabilities for each filing unit, both computed from TAXSIM. The first value is the tax liability that results from applying 1986 tax law to actual reported 1986 income and dependent exemptions. The second value adds one to the number of dependents claimed.

responses to benefits of this size. Whittington, Alm and Peters (1990) estimate that TRA86's increase in the personal exemption, from $\$ 1080$ to $\$ 2000$, raised the number of births by 7.53 per thousand women at risk, though these estimates have been called into question (Crump, Goda and Mumford 2011). Dickert-Conlin and Chandra (1999) estimate that a $\$ 500$ benefit would increase the fraction of mothers who give birth in the last week of December rather than the first week of January, so as to accelerate tax savings, by $26.9 \%$. The fact that existing research estimates that real behavioral responses are induced by tax savings of this magnitude suggests that these savings are "large" in some behavioral sense. This affirms our claim that foregoing these benefits due to a taste for honesty is a phenomenon of important magnitude. 


\subsection{Might audit risk explain a low prevalence of cheating?}

Evading taxes is risky. The average tax benefits from claiming an extra dependent are, ex ante, eroded by the possibility of detection and subsequent fines. To determine how much this audit risk lowers the benefits of cheating, we adapt the tax evasion model of Allingham and Sandmo (1972). Allingham and Sandmo (1972) model a risk averse taxpayer making a decision about what fraction of his tax bill to evade in order to maximize expected utility in a static setting. We modify this structure in two ways. First, we add a non-pecuniary cost of cheating, which allows for the possibility that taxpayers have a distaste for lying to the government (equivalently, a willingness to pay to be honest). Second, rather than model a continuous choice about how much to evade as in Gordon (1989), we model a discrete evasion decision, meant to mimic the decision about claiming an incremental fictitious dependent. This setup is useful in that it formalizes our parameter of interest, the willingness to pay to be honest, in an optimizing framework.

We assume that the filer's utility function exhibits constant relative risk aversion, with utility given by

$$
U(z)=\frac{z^{1-\gamma}}{1-\gamma}
$$

where $z$ is net income (assumed to be equivalent to consumption) and $\gamma$ is the coefficient of relative risk aversion. Filers choose whether to claim the appropriate number of dependents, in which case they receive their true after-tax income $Y$ with certainty. Alternatively, filers may choose to claim an additional, inappropriate dependent, which may reduce their taxes paid but also triggers a psychological cost of cheating, measured in dollars. If a cheating filer is caught he incurs an additional monetary penalty. For filer $i$, the payoffs are written as:

$$
\begin{aligned}
U_{i}(\text { Honesty }) & =\frac{Y_{i}^{1-\gamma}}{1-\gamma} \\
U_{i}(\text { Cheating }) & =(1-p) \frac{\left(Y_{i}+\Delta T_{i}-\theta_{i}\right)^{1-\gamma}}{1-\gamma}+p \frac{\left(Y_{i}-\phi \Delta T_{i}-\theta_{i}\right)^{1-\gamma}}{1-\gamma},
\end{aligned}
$$

where $p$ is the probability of audit, $\Delta T_{i}$ is the tax savings from cheating, $\phi$ is the penalty for cheating (expressed as a fraction of the amount evaded), and $\theta$ is the monetized psychological cost 
of cheating. ${ }^{15}$ We assume that all audits are successful in detecting any improper dependent claims.

A filer will choose to cheat if the expected payoff to cheating exceeds the expected payoff to honesty, accounting for risk aversion and the distaste for deceit. Thus, filers cheat if and only if

$$
(1-p) \frac{\left(Y_{i}+\Delta T_{i}-\theta_{i}\right)^{1-\gamma}}{1-\gamma}+p \frac{\left(Y_{i}-\phi \Delta T_{i}-\theta_{i}\right)^{1-\gamma}}{1-\gamma}>\frac{Y_{i}^{1-\gamma}}{1-\gamma}
$$

This formula does not yield a closed form solution for $\theta$, but the left-hand side is monotonically decreasing in $\theta$ so that, all else equal, a filer will cheat so long as $\theta$ is below some critical threshold, which we will label $G$. $G_{i}$ is the psychological cost that would make filer $i$ indifferent between cheating and not cheating, defined implicitly as:

$$
(1-p) \frac{\left(Y_{i}+\Delta T_{i}-G_{i}\right)^{1-\gamma}}{1-\gamma}+p \frac{\left(Y_{i}-\phi \Delta T_{i}-G_{i}\right)^{1-\gamma}}{1-\gamma}=\frac{Y_{i}^{1-\gamma}}{1-\gamma}
$$

A tax filer will cheat by claiming an extra dependent if and only if $\theta_{i} \leq G_{i}$. This critical value $G_{i}$ is an implicit function of the other parameters, including income, taxes saved by cheating, the penalty, risk aversion and the probability of audit. To determine how much risk assessment erodes the nominal value of cheating, we can calculate $G$, given parameter values for the other variables, and compare $G$ to $\Delta T$. If the two are similar, it means that risk has little impact on the nominal value of cheating - you would have to take away a large amount of money for sure in order to make the decision-maker indifferent between cheating and not.

Table 3 presents results from this exercise. We start by calculating the value for someone with the mean after-tax income in our 1986 sample of filers who did not lose a dependent in 1987, which is $\$ 21,670$. We model a tax savings equal to the mean in our sample for these filers, $\$ 275$. The fraction of tax returns audited in 1986 was around $2 \%$, so we begin with $p=.02$ as our baseline probability of detection. ${ }^{16}$ For risk aversion, we begin with $\gamma=2$, which is close to estimates in Chetty (2006) and Attanasio and Paiella (2011). There are two classes of penalties for underpayment of taxes, described in sections 6662 and 6663 of the Internal Revenue Code. Any part of underpayment due to "negligence or disregard of rules or regulations" is subject to a $20 \%$ penalty, while any part of

\footnotetext{
${ }^{15}$ We have in mind an internal cost that is independent of whether cheating is discovered and publicized, in contrast to a notion of shame felt only when any wrong-doing is made known to others.

${ }^{16}$ Between 1977 and 1986, the audit rate gradually fell from 1.88\% to 1\% (Dubin, Graetz and Wilde 1990). Between 1988 and 1995, the audit rate ranged between values of $0.92 \%$ and $1.67 \%$ (General Accounting Office 1996).
} 
Table 3: Sample Values of the Role of Risk

\begin{tabular}{|ccccc|cc|}
\hline$Y$ & $\Delta T$ & $\gamma$ & $p$ & $\phi$ & $G$ & $p^{*}$ \\
\hline 21,670 & 275 & 2 & .02 & .2 & 268 & .83 \\
21,670 & 275 & 2 & .02 & .75 & 265 & .57 \\
21,670 & 275 & 10 & .02 & .75 & 264 & .54 \\
21,670 & 275 & 100 & .02 & .75 & 242 & .31 \\
\hline 10,835 & 275 & 2 & .02 & .2 & 268 & .83 \\
2,167 & 275 & 2 & .02 & .2 & 267 & .81 \\
10,835 & 275 & 10 & .02 & .2 & 267 & .81 \\
2,167 & 275 & 10 & .02 & .2 & 259 & .72 \\
10,835 & 275 & 10 & .02 & .75 & 263 & .52 \\
2,167 & 275 & 10 & .02 & .75 & 238 & .31 \\
\hline 21,670 & 275 & 2 & .2 & .2 & 208 & $\cdot$ \\
10,835 & 275 & 10 & .2 & .75 & 160 &. \\
21,670 & 275 & 2 & .4 & .2 & 142 &. \\
10,835 & 275 & 10 & .4 & .75 & 56 &. \\
21,670 & 275 & 2 & .6 & .2 & 76 &. \\
10,835 & 275 & 10 & .6 & .75 & -38 &. \\
\hline
\end{tabular}

Table shows pretax income $Y$, the change in taxes paid from evasion $\Delta T$, the coefficient of absolute risk aversion $\gamma$, the probability of audit $p$, the IRS penalty as a fraction of taxes evaded $\phi$, the break-even willingness to pay to be honest, which makes a taxpayer indifferent between cheating and not $G$, and the probability of audit that would make the taxpayer indifferent between cheating and not if $G=0, p^{*}$.

underpayment attributable to fraud is subject to a $75 \%$ penalty. If taxpayers can claim plausible confusion about their mispayment, they will pay the $20 \%$ rate, which applies to the vast majority of cases. We use this as our baseline, so $\phi=.2$. Throughout this exercise, we assume filers are not cheating in any way other than misclaiming a dependent.

The first row of table 3 shows our baseline estimates. An individual who could save $\$ 275$ in taxes by improperly claiming a dependent would be willing to do so as long as his psychological cost of cheating is below $\$ 268$. This suggests that, for our baseline parameters, risk is not an important explanation for why so many taxpayers failed to cheat. Another way to see this is to calculate the probability of audit that would make a filer indifferent between cheating and not cheating, which we label as $p^{*}$, given the other parameters and assuming $G=0$. For our baseline case, that break-even probability is an extremely high $83 \%$.

For robustness, we vary these parameters, starting with the risk coefficient $\gamma$. The top panel 
shows that, even at the higher IRS penalty rate, raising the risk coefficient 50-fold has a negligible impact on the value of cheating. ${ }^{17}$ The middle panel of table 3 shows what happens when we lower the starting income value to one-half of the mean, which is the 34th percentile of our non-cheating 1986 sample, or one-tenth of the mean, which is the 6th percentile. Even at higher values of risk aversion and with the higher IRS penalty and very low starting income, risk assessment only lowers the value of cheating by about $13 \%$.

The only parameter that substantially changes the value of cheating is the probability of audit, which is shown in the third panel. Obviously, if filers believe that the probability of audit is $100 \%$, then cheating would never be worth doing under any circumstances. If filers believe the probability of being caught is $20 \%$, instead of the generic $2 \%$, then the payoff falls by around one-quarter, to \$208. If we assume the higher risk aversion, halve income, and raise the penalty rate, then this estimate falls further to $\$ 160$. Table 3 also shows what happens if the chance of getting caught is $40 \%$ or $60 \%$. This further erodes the value, but note that cheating is still a net positive, except in the very last scenario, which combines all of the most extreme assumptions.

Might taxpayers believe the probability of audit is extremely high? Precise survey data are not available, but some information about perceived audit probabilities is available from the 1987 Taxpayer Opinion Survey. When asked about the likelihood of their 1986 returns being audited, $35 \%$ of respondents said it was not very likely, $42 \%$ said it was highly unlikely, and another $15 \%$ were not sure. Might taxpayers believe that conditional on claiming an additional dependent the probability of audit is extremely high? The IRS does use a formula to determine audits (the Discriminant Index Function), but it is highly unlikely that claiming a dependent can change the formula by much. Even if all audits were confined to returns with dependents, this would have a modest impact on audit probabilities, relative to the differences needed to alter values qualitatively in table 3. This is another advantage of our study - we analyze an evasion opportunity that is especially unlikely to trigger audit. ${ }^{18}$

\footnotetext{
${ }^{17}$ Estimates of the coefficient of relative risk aversion based on observed equity return premiums are in the neighborhood of 50 (DeLong and Magin 2009).

${ }^{18}$ It is plausible that frequent changes in the number of dependents claimed might trigger audit. If so, the decision to falsely claim a dependent in one year might lock a taxpayer into making the same false claim for several years. We have investigated whether the 1987 dependent losers have unusually high variance in the number of dependents claimed across earlier years, as would be the case if cheaters fabricate dependents for just one or a few years at a time. There is no evidence of differences in the variance of children claimed for likely cheaters and for likely honest taxpayers.
} 
This framework formalizes the economic interpretation of our data from the 1986 reform. Those people who did not cheat must have a $\theta_{i} \geq G_{i}$, where $G_{i}$ will be roughly $97.5 \%$ of the estimated tax savings in table 2 for our base case, and well over $90 \%$ for even the most extreme scenarios, unless taxfilers believe their probability of being caught is much higher than the actual audit rates. Based on this, we conclude that the taste for honesty is substantial, even accounting for risk. ${ }^{19}$

\subsection{Might ignorance explain a low prevalence of cheating?}

An alternative interpretation is that filers who did not claim fictitious dependents prior to the reform were not doing so out of love of country, but instead because the opportunity to cheat had simply never occurred to them. Unfortunately, there is no way to directly measure the number of people who lacked the insight to cheat in this way. That said, this evasion opportunity is very simple and easy to achieve. It is also especially transparent, as the box for dependents claimed is right at the top of the 1040, as shown in figure 1. Moreover, if filers do not have a distaste for cheating, then we would expect them to invest some time in searching for low-hanging evasion fruit, like the dependent exemption. If filers were ignorant because they had no intention of cheating and therefore did not look for easy ways to cheat, then this is a round about way of affirming our hypothesis that they are willing to pay to be honest.

We suspect that people who claimed dependents at some point in time, and particularly those who had a change in the number of dependents, are aware of the tax value of dependents and the limited information required to claim those dependents prior to the reform. For filers who appear in all years of the tax panel, $66 \%$ had a dependent at some point in time, and $59 \%$ have a change in the number of dependents claimed during the sample period. ${ }^{20}$ Narrowing in on a group likely to be honest, filers who do not lose a dependent between 1986 and 1987, 34\% are claiming a dependent, and $32 \%$ had changed the number of dependents before 1986. This suggests that there is a substantial opportunity to learn about the potential gains from claiming dependents and the relative ease of doing so.

\footnotetext{
${ }^{19}$ In principle, estimates of the distribution of the willingness to pay to be honest could be estimated by comparing the amount of cheating at different tax values, given an additional assumption about the joint distribution of $\Delta T$ and $G$. We pursued this empirical strategy but determined that the available tax panel data are of insufficient sample size given the observed variation in tax values to produce meaningful estimates.

${ }^{20}$ For filers who appear at least once in the panel, $44 \%$ had a dependent at some point and $27 \%$ have an observed change in number of dependents claimed.
} 
In sum, there is no way to know whether any particular individual who failed to use the child loophole to lower his tax bill did so out of ignorance. Moreover, it is impossible to know what fraction of the honest taxpayers fall into that category. It seems likely, however, that filers with a thirst for cheating would have come across this possibility, particularly if they had experience with dependent exemptions, as most taxpayers do.

\section{Who cheated and why?}

\subsection{Cheaters have differences in tax return characteristics}

Who cheated? Are they different from honest payers on observable characteristics? To answer such questions, we would ideally like to know who cheated in pre-reform years, and compare their characteristics to honest taxpayers. Our panel data allow us to identify those who lost a dependent

in 1987 , but there is no immediate way to distinguish those who lost a dependent for legitimate reasons from cheaters who reacted to the reform.

Fortunately, we can detect large differences in observable characteristics between cheaters and non-cheaters by looking at changes in summary statistics across treatment years, where the number of cheaters present in particular subsamples varies widely and measurably. We pursue three different comparisons that use this basic approach. All three combine mild distributional assumptions with estimates of the number of cheaters in particular subsamples (taken from changes in observable statistics in response to the policy reform) to uncover facts about the characteristics of cheaters. These approaches may prove useful in other contexts. Here, they are especially compelling because all three approaches yield similar estimates, indicating that cheaters were more likely to be heads of household, less likely to be married filing jointly, and more likely to claim the Child Care Credit.

First, suppose that cheaters and non-cheaters have different distributions for some characteristic $X$. If the set of 1987 dependent losers includes a substantial number of cheaters, then the value of taxpayer characteristics among those who lost a dependent will be different in 1987 than in earlier years. This assumes that anyone losing a dependent in an earlier year, when misclaiming a dependent was quite simple and involved little risk of detection, must be honest. Specifically, the mean value of characteristic $X$ among all those who lost a dependent in 1987, denoted $\mu_{x}$, can be written as a weighted sum of the mean of $X$ for cheaters $\mu_{x}^{c}$ and non-cheaters $\mu_{x}^{h}$, where the weights 
are equal to the probability that someone in the sample is a cheater $\rho$ :

$$
\mu_{x}=\rho \mu_{x}^{c}+(1-\rho) \mu_{x}^{h}
$$

This equation can be rearranged to form an equation for the difference in means between cheaters and non-cheaters:

$$
\mu_{x}^{c}-\mu_{x}^{h}=\left(\mu_{x}-\mu_{x}^{h}\right) / \rho
$$

Thus, given an estimate of the pooled mean $\mu_{x}$, the mean of honest taxpayers $\mu_{x}^{h}$, and the proportion of the 1987 sample that were cheaters $\rho$, we can calculate an estimate of the difference in mean characteristics between cheaters and non-cheaters. We have a ready estimate of $\mu_{x}$ from our sample of returns, since it is simply the mean of all 1987 dependent losers. In section 4 we estimated that $31 \%$ of those losing a dependent in 1987 were cheaters, which provides an estimate of $\rho$.

To obtain an estimate of $\mu_{x}^{h}$ we use the mean of characteristic $X$ for filers reporting a dependent loss in an earlier year. TRA86 created many changes in the tax code that might cause differences in observable characteristics. To avoid conflating these changes with the differences between cheaters and non-cheaters, we measure the characteristics of the 1987 dependent losers in 1986, the year prior. For consistency, we compute means in the year before dependent loss for the comparison group of honest taxpayers.

Table 4 shows the results of this exercise. Column 1 shows the sample mean of characteristics listed measured in 1985 for taxpayers who lost a dependent in 1986. This is our estimate of the mean characteristic for honest taxpayers who lose a dependent. Column 2 shows the mean characteristic on 1986 tax returns (before the reform), for those taxpayers who lost a dependent in 1987 (when the reform took effect). Asterisks indicate that this value is statistically different from column 1 at the $10 \%$ level based on a simple comparison of means. Column 3 shows our estimate of the difference in each characteristic between cheaters and honest losers of dependents, based on equation 7 and assuming $\rho=0.31$.

Column 3 of table 4 shows that there are significant differences between cheaters and those who lost a dependent for legitimate reasons. In particular, cheaters were much less likely to be 
Table 4: Summary Statistics for Filers Losing a Dependent

\begin{tabular}{|c|c|c|c|c|c|}
\hline & \multirow{3}{*}{$\begin{array}{c}\text { Lost Dep } \\
\text { in } 1986 \\
\left(\widehat{\mu_{x}^{h}}\right)\end{array}$} & \multirow{3}{*}{$\begin{array}{c}\text { Lost Dep } \\
\text { in } 1987 \\
\left(\widehat{\mu_{x}}\right)\end{array}$} & \multirow{3}{*}{$\begin{array}{c}\text { Mean Diff: } \\
\text { Cheaters - } \\
\text { Honest } \\
\left(\mu_{x}^{c}-\mu_{x}^{h}\right)\end{array}$} & \multicolumn{2}{|c|}{$\begin{array}{c}\text { Among } 1987 \text { Losers: } \\
\text { Lost Previously? }\end{array}$} \\
\hline & & & & Yes & No \\
\hline & & & & (Honest) & (Cheaters) \\
\hline & $(1)$ & $(2)$ & $(3)$ & $(4)$ & $(5)$ \\
\hline$\%$ Married, year $t-1$ & 69.9 & $62.3^{*}$ & -24.5 & 71.1 & $54.5^{*}$ \\
\hline$\%$ Head of Household, year $t-1$ & 23.3 & $31.1^{*}$ & 25.2 & 23.5 & $37.7^{*}$ \\
\hline$\%$ with Change in Filing Status & 21.1 & 24.7 & 11.6 & 19.0 & $29.6^{*}$ \\
\hline$\%$ with Change in State & 3.6 & 4.2 & 1.9 & 3.3 & 4.9 \\
\hline Mean dependents, year $t-1$ & 2.1 & 2.3 & 0.6 & 2.1 & $2.4^{*}$ \\
\hline Mean $\Delta$ in number of Deps & -1.2 & $-1.3^{*}$ & -0.3 & -1.2 & $-1.4^{*}$ \\
\hline Zero Dependents after Loss & 47.9 & 44.1 & -12.3 & 47.3 & 41.3 \\
\hline Head of HH to Single after Loss & 10.4 & 13.2 & 9.0 & 10.4 & $15.6^{*}$ \\
\hline Last Dependent Had no Tax Value & 7.3 & 5.4 & -6.1 & 3.6 & $7.0^{*}$ \\
\hline$\%$ with Child Care Credit, year $t-1$ & 7.8 & $12.8^{*}$ & 16.1 & 10.1 & $15.1^{*}$ \\
\hline$\%$ with EITC, year $t-1$ & 13.1 & 14.8 & 5.5 & 13.4 & 16.1 \\
\hline$\%$ age 65 or older as of 1987 & 6.0 & 4.4 & -5.2 & 4.2 & 4.7 \\
\hline$\%$ age 65 or older as of 1990 & 9.5 & 7.5 & -6.5 & 8.0 & 7.0 \\
\hline Mean AGI $(\$)$, year $t-1$ & 35,695 & 35,550 & -468 & 40,250 & $31,448^{*}$ \\
\hline$\%$ itemizing, year $t-1$ & 53.6 & 49.0 & -14.8 & 56.5 & $42.3^{*}$ \\
\hline$\%$ contrib. IRA, year $t-1$ & 21.7 & $16.5^{*}$ & -16.8 & 20.2 & $13.2^{*}$ \\
\hline$\%$ contrib. election fund, year $t-1$ & 31.7 & $25.2^{*}$ & -21.0 & 21.7 & $28.3^{*}$ \\
\hline $\mathrm{N}$ & 549 & 721 & & 336 & 385 \\
\hline
\end{tabular}

Dollar amounts are in real 1990 dollars. The * indicates difference between preceding two columns is statistically significant at the $10 \%$ level or better. Column 3 is the estimated difference in means between cheaters and honest taxpayers, equal to (column 2 - column 1)/.31. Column 4 is hypothesized to have a substantially higher percentage of honest taxpayers than column 5 , so that the sign of the difference is indicative of the difference in means between groups.

married filing jointly, and much more likely to file as head of household. Moreover, far more cheaters experienced a change in their filing status in 1987. This is driven in large part by 1986 head of household filers shifting to the less generous single filing status in 1987, though the difference is statistically imprecise. Head of household filing status is only available to unmarried individuals with children. Cheaters were also much more likely to claim the Child Care Credit, which is a tax credit for child care expenses incurred to enable parents or guardians to work. Taken together, the evidence shows that cheaters gained not only from claiming an additional dependent exemption, but also from moving to the head of household rate schedule and claiming (possibly fraudulent) 
credits for child care expenses. ${ }^{21}$ Cheaters were also less likely to contribute to an IRA and to make a contribution to the presidential election campaign fund (which is plausibly correlated with a sense of civic engagement). Other characteristics fail to show a statistically significant difference.

A second, related method of identifying differences in characteristics of cheaters and honest taxpayers comes from delineating two subgroups within the set of filers who lost a dependent in 1987. We hypothesize that having lost a dependent in years prior to the reform, when there was no change in the enforcement technology for detecting misclaimed dependents, is an indication of honesty. Thus, the group of individuals who lost dependents in 1987 and in earlier years likely contains a high proportion of honest taxpayers. The group of individuals who lost dependents in 1987 but never before likely contains a higher proportion of cheaters. Table 4 shows the means across these two subgroups, which are of roughly equal size, in columns 4 and 5 . Asterisks in column 5 indicate that there is a statistically significant difference at the $10 \%$ level using a simple comparison of means across the two columns.

This alternative procedure shows the same qualitative results about filing status as the analysis in columns 1-3. First-time dependent losers were less likely to be married filing jointly in 1986, and more likely to be filing as a head of household. Many more first-time losers experienced a change of filing status in 1987. Similarly, significantly more first-time losers claimed the Child Care Credit in 1986. This alternative comparison also suggests that differences in AGI, the fraction itemizing, the fraction contributing to an IRA, and the fraction contributing to the election fund are statistically different. With the exception of election fund contributions, the differences go in the same direction as in the previous comparison of cheaters and honest filers.

To address likely correlations across taxpayer characteristics, we next estimate a probit regression predicting dependent loss. We pool filers who are observed in two consecutive years up to and including 1987, and restrict the sample to those claiming at least one dependent in the earlier year of each pair. We control for a number of taxpayer characteristics, and interact each of these characteristics with a dummy for 1987 observations. This allows us to test whether a given characteristic affects the probability of dependent loss differently in the year when many losses represent cheating.

\footnotetext{
${ }^{21}$ The IRS began requiring a Social Security Number or Taxpayer Identification Number for the care provider for anyone claiming the Child Care Credit in 1989. As discussed in O'Neil and Lanese (1993) and cited by Slemrod and Bakija (2008) (pp. 238-9), this reform was followed by a substantial increase in the number of claims of selfemployment income, a response similar in spirit to what we analyze here.
} 
Table 5: Probit Regression Predicting Dependent Loss

\begin{tabular}{lcc}
\hline \hline & Coefficient & Coefficient \\
Married, year $t-1$ & -0.026 & 0.006 \\
& $(0.031)$ & $(0.068)$ \\
Head of Household, year $t-1$ & $0.070^{* *}$ & $0.184^{* *}$ \\
& $(0.034)$ & $(0.081)$ \\
Change in Filing Status & $1.049^{* * *}$ & $0.234^{* * *}$ \\
& $(0.025)$ & $(0.084)$ \\
Number of dependents, year $t-1$ & $0.185^{* * *}$ & $0.111^{* * *}$ \\
& $(0.006)$ & $(0.023)$ \\
Any Child Care Credit, year $t-1$ & $-0.543^{* * *}$ & 0.059 \\
& $(0.028)$ & $(0.075)$ \\
Any EITC, year $t-1$ & $-0.059^{* * *}$ & 0.048 \\
& $(0.022)$ & $(0.086)$ \\
Age 65 or older as of 1987 & $0.624^{* * *}$ & 0.016 \\
& $(0.036)$ & $(0.150)$ \\
Any IRA contribution, year $t-1$ & $0.183^{* * *}$ & -0.103 \\
& $(0.026)$ & $(0.075)$ \\
Real AGI, year $t-1$ (1000s) & $0.0003^{* *}$ & -0.0003 \\
N & $(0.0001)$ & $(0.0006)$ \\
\hline \hline
\end{tabular}

The sample includes filers at risk of losing a dependent between 1980 and 1987, those who claimed at least one dependent in the previous tax year. The dependent variable is a dummy variable coded as 1 if the filer lost a dependent between years $t-1$ and $t$. The ${ }^{*},{ }^{*}$ and $* * *$ indicate statistical significance at the $10 \%, 5 \%$ and $1 \%$ levels.

The results are shown in Table 5. In this specification, only measures of household composition appear to be associated with cheating. While filing as head of household, relative to filing as a single taxpayer, is always associated with a significantly higher probability of dependent loss, this effect is larger in 1987. The same is true for having experienced a change in filing status between the two consecutive tax years. Other characteristics appear to affect dependent loss in the same way in 1987 as in earlier years. Broadly, the results corroborate our conclusions above.

Third, we use a different decomposition to infer the difference in characteristics across honest taxpayers and cheaters. The prior two methodologies were premised on a comparison of taxpayers who lost a dependent at different times, under different enforcement regimes. We can also compare filers who lost a dependent to filers who gained a dependent. ${ }^{22}$ We start by noting that the mean of some characteristic $X$, among those who gain a dependent (henceforth "a gainer") in a given

\footnotetext{
${ }^{22}$ We are especially grateful to Damon Jones for suggesting this approach.
} 
tax year $t$, can be written as the weighted sum of the mean of that characteristic for cheaters and honest taxpayers, where the weight is the probability that a gainer in year $t$ is a cheater:

$$
\mu_{x, t}^{g}=\rho_{t}^{g} \mu_{x, t}^{g, c}+\left(1-\rho_{t}^{g}\right) \mu_{x, t}^{g, h}
$$

Here $\mu_{x, t}^{g}$ is the average characteristic for gainers in year $t$ (which is directly observable), $\mu_{x, t}^{g, c}$ is the average characteristic for gainers who are cheaters in year $t, \mu_{x, t}^{g, h}$ is the average characteristic for gainers who are honest in year $t$, and $\rho_{t}^{g}$ is the probability that a gainer is a cheater in year $t$. The same decomposition can be written for those who lose a dependent ("losers") in a given year: $\mu_{x, t}^{l}=\rho_{t}^{l} \mu_{x, t}^{l, c}+\left(1-\rho_{t}^{l}\right) \mu_{x, t}^{l, h}$.

If we make assumptions about the stability of mean characteristics for cheaters and honest taxpayers, then a comparison of the change in mean characteristics of gainers and losers spurred by a change in enforcement (which is observable) can be used to infer the difference in mean characteristics of cheaters and honest types (which is not directly observable). Specifically, we assume that cheaters have the same characteristic mean, in both 1986 and 1987, regardless of whether they are gainers or losers. That is, $\mu_{x, 87}^{g, c}=\mu_{x, 87}^{l, c}=\mu_{x, 86}^{g, c}=\mu_{x, 86}^{l, c} \equiv \mu_{x}^{c}$. We make a parallel assumption for honest taxpayers: $\mu_{x, 87}^{g, h}=\mu_{x, 87}^{l, h}=\mu_{x, 86}^{g, h}=\mu_{x, 86}^{l, h} \equiv \mu_{x}^{h}$. Under these assumptions, it is straightforward to show that the difference in the mean characteristics between gainers and losers can be written as:

$$
\mu_{x, t}^{g}-\mu_{x, t}^{l}=\left(\rho_{t}^{g}-\rho_{t}^{l}\right)\left(\mu_{x, t}^{c}-\mu_{x, t}^{h}\right)
$$

This same expression can be calculated for years before and after a reform that changes the probability that gainers and losers are cheaters in estimable ways. Writing out the difference in difference between characteristics of gainers and losers across years $\left(\left(\mu_{87, t}^{g}-\mu_{87, t}^{l}\right)-\left(\mu_{86, t}^{g}-\mu_{86, t}^{l}\right)\right)$ using equation 9 and rearranging yields an expression for the difference in means across cheaters and honest taxpayers, our object of interest:

$$
\mu_{x}^{c}-\mu_{x}^{h}=\frac{\left(\mu_{x, 87}^{g}-\mu_{x, 87}^{l}\right)-\left(\mu_{x, 86}^{g}-\mu_{x, 86}^{l}\right)}{\left(\rho_{87}^{g}-\rho_{86}^{g}\right)-\left(\rho_{87}^{l}-\rho_{86}^{l}\right)} .
$$


The left-hand side of equation 10 is exactly the same object as the one estimated by our first method and shown in column 3 of table 4 . The numerator on the right-hand side is the differencein-difference across gainers and losers from 1986 to 1987. Each object in the numerator is directly observable. The denominator is the difference-in-difference in the probability that gainers and losers are cheaters between 1986 and 1987. Intuitively, this inference procedure examines the differencein-difference in a characteristic across gainers and losers - groups whose fraction of cheaters should change sharply in 1987. The difference-in-difference inflated by the change in fraction of cheaters present in each pool yields an estimate of the difference between cheaters and honest taxpayers.

The probabilities in the denominator are not observable directly, but they can be inferred with relative precision under the assumption that the only reason that there were more losers and fewer gainers in 1987 was the reaction of cheaters to the introduction of the SSN requirement for dependents. Then, the change in the number of taxpayers gaining or losing a dependent provides an estimate of the change in the probability that a gainer (loser) was a cheater. ${ }^{23}$ Proceeding under that assumption, we can use equation 10 to calculate an estimate of the mean difference in characteristics across cheaters and honest taxpayers.

Table 6 shows the results of this exercise. Our previous estimates of $\mu_{x}^{c}-\mu_{x}^{h}$, from table 4 , are shown in column 1. Several characteristics from table 4 are omitted because they apply only to dependent losers, and the second methodology requires means for gainers. The second column shows estimates from the difference-in-difference decomposition for dependent gainers and losers. Overall, the results are strikingly similar, given that they come from the comparison of different subsamples and are motivated by different assumptions. The sign of the estimated difference is the same for all characteristics except our measure of geographic mobility (changing states), which was not statistically different in our first comparison. Moreover, the magnitude of the difference is qualitatively similar for most variables. This reaffirms our conclusion that cheaters were less likely to be married, more likely to be heads of household and more likely to claim the Child Care Credit.

Our first decomposition relied on the assumption that the mean characteristic for taxpayers who lost a dependent in 1986 was an unbiased estimate of the mean characteristic of honest taxpayers

\footnotetext{
${ }^{23}$ An assumption about exactly how many cheaters were in each group in 1986 is still required because this influences the denominator in the probability calculations. We assume that no one losing a dependent in 1986 is a cheater, and that no one gaining a dependent in 1987 is a cheater. Modifying these assumptions has a very modest impact on our estimates.
} 
Table 6: Differences Between Cheaters and Honest Taxpayers

\begin{tabular}{lcc}
\hline \hline & $\begin{array}{c}\text { Based on Timing } \\
\text { of Dependent Loss }\end{array}$ & $\begin{array}{c}\text { Based on Comparison } \\
\text { of Gainers and Losers }\end{array}$ \\
\cline { 2 - 3 } \% Married, year $t-1$ & $(1)$ & $(2)$ \\
\% Head of Household, year $t-1$ & -24.5 & -29.8 \\
\% with Change in Filing Status & 25.2 & 34.6 \\
\% with Change in State & 11.6 & 14.6 \\
Mean dependents, year $t-1$ & 1.9 & -6.0 \\
\% with Child Care Credit, year $t-1$ & 0.6 & 0.9 \\
\% with EITC, year $t-1$ & 16.1 & 7.4 \\
\% age 65 or older as of 1987 & 5.5 & 13.7 \\
\% age 65 or older as of 1990 & -5.2 & -8.3 \\
Mean AGI (\$), year $t-1$ & -6.5 & -9.8 \\
\% itemizing, year $t-1$ & -468 & -4.723 \\
\% contributing to IRA, year $t-1$ & -14.8 & -27.1 \\
\% contributing to election fund, year $t-1$ & -16.8 & -26.2 \\
\hline \hline
\end{tabular}

Column 1 repeats the estimate of the difference in the mean of the characteristic for cheaters and honest types from table 4 . The second column is an estimate of the same parameter (the difference in the mean of the characteristic for cheaters and honest types) based on the difference-in-difference statistic from equation 10.

who lost a dependent in 1987. In the second decomposition, we instead make the assumption that honest taxpayers have the same mean characteristic in 1986 and 1987, regardless of whether they are gainers or losers. Similarly, we assume that cheating taxpayers who gain a dependent in 1986 have the same mean characteristics as cheating taxpayers who lose a dependent in 1987. (As a reminder, we are measuring characteristics in year $t-1$, so the mean characteristics are not influenced by the changes in the tax code included in TRA86 in either method.) Neither assumption is free of potential criticism, but having two distinct sets of assumptions allows us to check for the robustness of our conclusions from the first methodology. ${ }^{24}$

\footnotetext{
${ }^{24}$ We have calculated parallel comparisons that compare 1987 to pooled means across $1980-1986$, which has the advantage of increasing the sample size. Most of our findings are robust to this change in comparison group, but the differences between the two methodologies is inflated for several characteristics, including claiming of the Child Care Credit, itemizing, and IRA contributions. This may not be surprising, however, because there are other changes in the tax code in that time period which make assumptions about stability of means across different time periods much stronger than in the two-year comparison.
} 


\subsection{Cheaters do not have particularly large tax benefits from dependents}

What explains the fact that some people cheat on their taxes by claiming inappropriate dependent exemptions and others do not? Is the difference driven mostly by variation in the willingness to pay to be honest, or mostly by variation in the tax savings associated with claiming an additional dependent? One possibility is that there is a limited amount of variation in the willingness to pay to be honest. In the extreme, suppose that all people have the same willingness to pay to be honest. Then, the only determinant of whether or not a person cheats is his tax gain from doing so. This implies that cheaters will have noticeably higher tax savings from the marginal dependent than will honest payers.

A second possibility is that there is considerable variation in the willingness to pay to be honest. In this scenario, the link between the monetary gain from cheating and the probability of cheating might be weak, depending on the correlation between tax savings (largely a function of income) and honesty. Assuming that tax savings and honesty are not too tightly correlated, as the variation in the willingness to pay to be honest rises, the relationship between cheating and tax savings from an additional dependent will dissipate. Thus, qualitatively, if there is a weak relationship between tax savings and cheating, we will conclude that heterogeneity in honesty is the primary determinant of cheating behavior, but we will conclude the opposite if the link is strong. ${ }^{25}$

To test whether or not tax savings are closely correlated with cheating, we first refer back to table 2, which shows the tax savings from changing the number of dependents for different subsamples. We focus on comparing the average tax savings of filers who lost a dependent in 1987, about onethird of whom are cheaters, to other groups of filers who contain few or no cheaters. Table 2 shows that those losing a dependent in 1987 had a mean tax savings for their last dependent claimed in 1986 of $\$ 253$ (the benefit from cheating for an observed cheater is the tax change associated with losing the marginal dependent claimed).

Groups devoid of cheaters had similar, or even slightly larger, tax savings from cheating. Those who claimed no dependents in 1986 clearly were not cheating. The benefit from cheating for that group is equal to the value of gaining a first dependent, which is on average $\$ 291$ in 1986 . Similarly,

\footnotetext{
${ }^{25}$ Note that this setup assumes relatively little variation in risk preferences and the probability of audit. Because risk has little impact on the valuation of evasion, this portion of the assumption is innocuous, but if there is substantial heterogeneity in the subjective probability assigned to being audited, then this could also play a significant role in explaining the decision to evade.
} 
Table 7: Tax Savings From Claiming A Dependent, All Years

\begin{tabular}{lccccc}
\hline \hline & \multicolumn{2}{c}{ Gain from One } & & \multicolumn{2}{c}{ Loss from One } \\
& \multicolumn{2}{c}{ More Dependent } & & \multicolumn{2}{c}{ Fewer Dependent } \\
\cline { 2 - 3 } \cline { 5 - 6 } Year $t-1$ & No Loss & Lost Dep & & No Loss & Lost Dep \\
& in $t$ & in $t$ & & in $t$ & in $t$ \\
& $(1)$ & $(2)$ & & $(3)$ & $(4)$ \\
\hline 1979 & 234 & 226 & & -274 & -266 \\
1980 & 243 & 240 & & -282 & -275 \\
1981 & 254 & 237 & & -289 & -279 \\
1982 & 240 & 229 & & -270 & -253 \\
1983 & 228 & 221 & & -259 & -249 \\
1984 & 223 & 219 & & -252 & -243 \\
1985 & 232 & 218 & & -266 & -254 \\
1986 & 243 & 224 & & -276 & -254 \\
1987 & 349 & 346 & & -428 & -415 \\
1988 & 340 & 313 & & -436 & -390 \\
1989 & 348 & 330 & -457 & -406 \\
\hline \hline
\end{tabular}

Estimates are author's calculations using TAXSIM.

those who had a dependent in 1986 but did not lose a dependent in 1987 are unlikely to be cheaters. This group had a mean tax value of $\$ 243$. The last row in table 2 shows these two groups combined. Together, they could have gained $\$ 275$ on average from claiming a false dependent. This indicates that cheaters and honest filers faced similar incentives.

An alternative way to infer the tax savings enjoyed by cheaters involves a comparison across different years. Table 7 presents the average tax savings associated with claiming a dependent in each year of our panel. We believe that the values in the $t-1=1986$ row of columns 2 and 4 contain a large number of cheaters. If cheaters have systematically higher tax savings from claiming a dependent, and if those who lost a dependent for legitimate reasons in 1987 had tax savings similar to those who lost a dependent in prior years, then we would expect particularly high tax savings in the $t-1=1986$ sample. Such a pattern is not evident. This sample had an average tax value of $\$ 254$ from losing their last dependent. This is exactly the same as the average value in the previous year, and quite similar to all of the values stretching back to the beginning of our sample in 1979. This is further evidence that cheaters and honest taxpayers had similarly-sized tax benefits from claiming a dependent.

Figure 6 goes beyond comparisons of means by plotting the empirical cumulative distribution of 


\section{Figure 6: Distribution of Tax Values}

(a) Lost Dependent in 1987

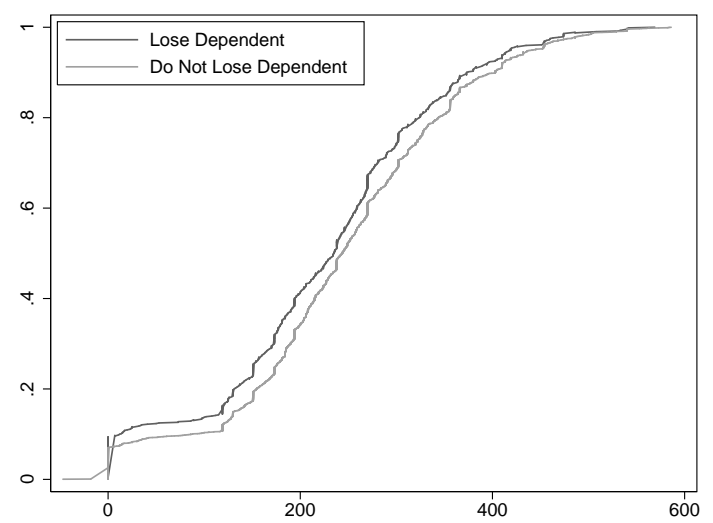

(c) Lost Dependent in 1987 (Non-zeros)

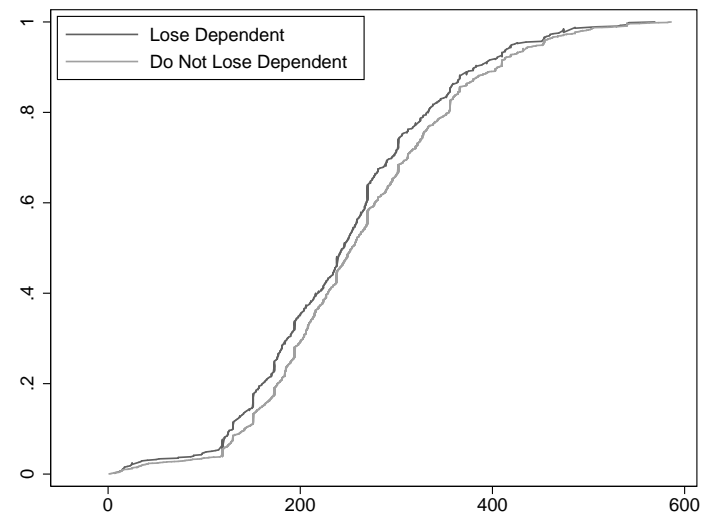

(b) Lost Dependent in 1980-1986

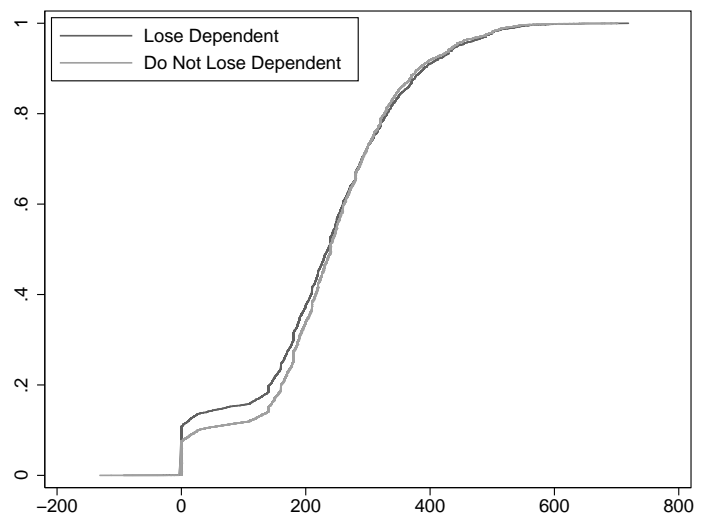

(d) Lost Dependent in 1980-1986 (Non-zeros)

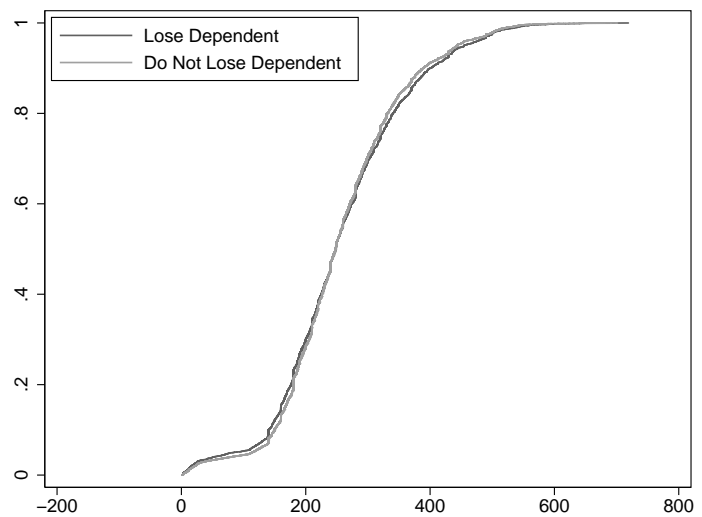

Figure shows empirical distributions of the tax savings associated with a marginal dependent for those losing a dependent and those not losing a dependent in the policy change year (a) and earlier years (b). Panels (c) and (d) show the same statistics for the subset of filers that have a non-zero tax value. All calculations are for tax values in year $t-1$, where $t$ is the year when the dependent was lost.

tax values for relevant subsamples. Figure 6 a shows the distribution for those who lost a dependent in 1987 and those who did not lose a dependent in 1987. If the driving force behind cheating is tax savings, we would expect that those who lost a dependent in 1987 - many of whom were cheaters would have higher tax values than those who did not cheat. This is not the case. The distribution for those losing a dependent lies above the distribution for those who did not lose a dependent, which implies that they had lower gains from claiming an additional dependent.

Figure $6 \mathrm{~b}$ shows the same comparison for years before the policy reform. This shows that 
the distributions are fairly similar, though there is a difference in the number with a zero tax value - more of those who lost a dependent in pre-1987 years had a zero value from an additional dependent. To eliminate any differences in the distribution due strictly to the zero values, figures $6 \mathrm{c}$ and $6 \mathrm{~d}$ show the same distributions, limited to those with positive estimated tax values. Now, the pre-reform years look very similar, which suggests that, when there is no change in the incentive to cheat, the tax value distributions of those losing a dependent and those not losing are quite similar. Nevertheless, the policy reform year still shows a difference - those who lost a dependent had lower tax values.

Overall, this evidence suggests that cheaters did not have especially large gains from claiming additional children. This implies that the main driver of the decision to cheat was not the amount of money at stake, but rather variation in the taste for honesty.

\section{Conclusion}

The case of the missing children provides a unique opportunity for examining taxpayers' evasion behavior. Two main lessons emerge from our analysis. First, this episode demonstrates that while a substantial number of taxpayers lied to the IRS in order to save on their taxes, a much larger fraction of taxpayers passed up an easily accomplished evasion opportunity. These honest taxpayers gave up hundreds of dollars of tax savings, which amounted to an average of $7 \%$ of their tax bill. This choice reveals a substantial and widespread willingness to pay to be honest. We think this is an important addendum to recent research that concludes that evasion is driven primarily by access to evasion opportunities and monitoring efficacy, as in Kleven et al. (2010). The evidence here suggests a greater role for a preference for honesty.

Second, the available evidence indicates that heterogeneity in willingness to cheat outweighed heterogeneity in the tax savings associated with children in determining who cheated and who did not. Cheaters do appear to be different from honest taxpayers, on average, in some key characteristics, like filing status, but these differences do not translate to substantial differences in the average tax savings from claiming children. This suggests that something other than variation in the tax benefit of a child plays an important role in determining who cheated and who did not. We interpret this as evidence that there is important variation in the willingness to pay to be 
honest.

Finally, we believe that our methodology for inferring the characteristics of cheaters, our use of a natural experiment, and our analysis of an evasion opportunity available to virtually all taxpayers constitute contributions to the larger literature on the economics of income tax evasion. In particular, our work contributes to the emerging research stream of research that studies "traces of evasion" (Slemrod and Weber Forthcoming) by showing an additional way of learning about evasion in the absence of audit data.

\section{References}

Allingham, Michael G. and Agnar Sandmo, "Income Tax Evasion: A Theoretical Analysis," Journal of Public Economics, 1972, 1, 323-338.

Alm, James, Gary H. McClelland, and William D. Schulze, "Why Do People Pay Taxes?," Journal of Public Economics, 1992, 48, 21-38.

Andreoni, James, Brian Erard, and Jonathan Feinstein, "Tax Compliance," Journal of Economic Literature, June 1998, 36 (2), 818-860.

Attanasio, Orazio P. and Monica Paiella, "Intertemporal Consumption Choices, Transaction Costs and Limited Participation in Financial Markets: Reconciling Data and Theory," Journal of Applied Econometrics, 2011, 26 (2), 322-343.

Baldry, Jonathan, "Income Tax Evasion and the Tax Schedule: Some Experimental Results," Public Finance, 1987, 42 (3), 357-383.

Becker, Gary S., "Crime and Punishment: An Economic Approach," Journal of Political Economy, March/April 1968, 76 (2), 169-217.

Becker, Winfried, Heinz-Jürgen Büchner, and Simon Sleeking, "The Impact of Public Transfer Expenditures on Tax Evasion," Journal of Public Economics, 1987, 34, 243-252.

Block, M.K. and J.M. Heineke, "A Labor Theoretic Analysis of the Criminal Choice," American Economic Review, June 1975, 65 (3), 314-325.

Bordignon, Massimo, "A Fairness Approach to Income Tax Evasion," Journal of Public Economics, 1993, 52, 345-362.

Chetty, Raj, "A New Method of Estimating Risk Aversion," American Economic Review, 2006, $96(5), 1821-1834$.

Christian, Charles W., "Voluntary Compliance with the Individual Income Tax: Results form the 1988 TCMP Study," In IRS Research Bulletin 1993/1994, Publication 1500 (Rev. 9-94) 1994.

Clotfelter, Charles T., "Tax Evasion and Tax Rates: An Analysis of Individual Returns," Review of Economics and Statistics, August 1983, 65 (3), 363-373.

Cowell, F.A., "Tax Evasion and Inequity," Journal of Economic Psychology, 1992, 13, 521-543. 
Crump, Richard, Gopi Shah Goda, and Kevin Mumford, "Fertility and the Personal Exemption: Comment," American Economic Review, June 2011, 101 (4), 1616-28.

DeLong, J. Bradford and Konstantin Magin, "The U.S. Equity Return Premium: Past, Present, and Future," Journal of Economic Perspectives, 2009, 23 (1), 193-208.

Dickert-Conlin, Stacy and Amitabh Chandra, "Taxes and the Timing of Births," Journal of Political Economy, February 1999, 107 (1), 161-177.

Dubin, Jeffrey A., Michael J. Graetz, and Louis Wilde, "The Effect of Audit Rates on the Federal Individual Income Tax, 1977-1986," National Tax Journal, December 1990, 43 (4), 395-409.

Erard, Brian and Jonathan S. Feinstein, "Honesty and Evasion in the Tax Compliance Game," RAND Journal of Economics, Spring 1994, 25 (1), 1-19.

Fack, Gabrielle and Camille Landais, "Charitable Giving and Tax Policy in the Presence of Tax Cheating: Theory and Evidence from the U.S. and France," April 2011. Manuscript: Stanford University.

Feenberg, Daniel and Elisabeth Coutts, "An Introduction to the TAXSIM Model," Journal of Policy Analysis and Management, 1993, 12 (1), 189-194.

Feinstein, Jonathan S., "An Econometric Analysis of Income Tax Evasion and its Detection," RAND Journal of Economics, Spring 1991, 22 (1), 233-276.

Feldman, Naomi E. and Joel Slemrod, "Estimating Tax Noncompliance with Evidence from Unaudited Tax Returns," The Economic Journal, March 2007, 117, 327-352.

Fisman, Raymond and Shang-Jin Wei, "Tax Rates and Tax Evasion: Evidence from "Missing Imports" in China," Journal of Political Economy, April 2004, 112 (2), 843-877.

General Accounting Office, "Erroneous Dependent and Filing Status Claims," March 1993. GAO/GGD-93-60.

_. "Audit Trends and Results for Individual Taxpayers," April 1996. GAO/GGD-96-61.

Gordon, James P. F., "Individual Morality and Reputation Costs as Deterrents to Tax Evasion," European Economic Review, 1989, 33, 797-805.

Gruber, Jonathan, Public Finance and Public Policy, third ed., Worth, 2009.

Internal Revenue Service Oversight Board, "2010 Taxpayer Attitude Survey," U.S. Department of the Treasury January 2011.

Jacob, Brian A. and Steven D. Levitt, "Rotten Apples: An Investigation of the Prevalence and Predictors of Teacher Cheating," Quarterly Journal of Economics, August 2003, 118 (3), 843-877.

Klepper, Steven and Daniel Nagin, "The Anatomy of Tax Evasion," Journal of Law, Economics, $\&$ Organization, Spring 1989, 5 (1), 1-24.

Kleven, Henrik J., Martin B. Knudsen, Claus T. Kreiner, Søren Pederson, and Emmanuel Saez, "Unwilling or unable to cheat? Evidence from a randomized tax audit experiment in Denmark," February 2010. NBER Working Paper No. 15769. 
Levitt, Steven D. and Stephen J. Dubner, Freakonomics, Harper Collins, 2005.

Liebman, Jeffrey B., "Who Are the Ineligible EITC Recipients?," National Tax Journal, December 2000, 53 (4), 1165-1185.

McCubbin, Janet, "EITC Noncompliance: The Determinants of the Misreporting of Children," National Tax Journal, December 2000, 53 (4), 1135-1164.

Oliva, Paulina, "Environmental Regulations and Corruption: Automobile Emissions in Mexico City," September 2010. Manuscript: University of California, Santa Barbara.

O'Neil, Cherie J. and Karen B. Lanese, "T.I.N. Requirements and the Child Care Credit: Impact on Taxpayer Behavior," 1993. Manuscript: University of South Florida.

Pissarides, Christopher A. and Guglielmo Weber, "An Expenditure-Based Estimate of Britain's Black Economy," Journal of Public Economics, 1989, 39, 17-32.

Slemrod, Joel, "Cheating Ourselves: The Economics of Tax Evasion," Journal of Economic Perspectives, Winter 2007, 21 (1), 25-48.

- and Caroline Weber, "Evidence of the Invisible: Toward a Credibility Revolution in the Empirical Analysis of Tax Evasion and the Informal Economy," International Tax and Public Finance, Forthcoming.

- and Jon Bakija, Taxing Ourselves: A Citizen's Guide to the Debate over Taxes, fourth ed., MIT, 2008.

Smith, Kent W.., "Reciprocity and Fairness: Positive Incentives for Tax Compliance," in "Why People Pay Taxes," University of Michigan Press, 1992, pp. 223-250.

Spicer, Michael W. and Lee A. Becker, "Fiscal Inequality and Tax Evasion: An Experimental Approach," National Tax Journal, June 1980, 33 (2), 171-175.

Szilagyi, John A., "Where Have All the Dependents Gone?," in "Trend Analyses and Related Statistics - 1990 Update," Vol. Internal Revenue Service Publication 1500, IRS, August 1990, pp. 63-72.

Tyler, Tom R., Why People Obey the Law, Yale University Press, 1990.

Whittington, Leslie A. and H. Elizabeth Peters, "Economic Incentives for Financial and Residential Independence," Demography, February 1996, 33 (1), 82-97.

_, James Alm, and H. Elizabeth Peters, "Fertility and the Personal Exemption: Implicit Pronatalist Policy in the United States," American Economic Review, June 1990, 80 (3), 545-556. 